\title{
Less Equal, Less Trusting? Longitudinal and Cross-sectional Effects of Income Inequality on Trust in U.S. States, 1973-2012
}

\author{
Orestes P. Hastings* \\ Colorado State University \\ Department of Sociology
}

Published in Social Science Research. Full citation:

Hastings, Orestes P. 2018. "Less Equal, Less Trusting? Reexamining Longitudinal and Cross-sectional Effects of Income Inequality on Trust in U.S. States, 1973-2012." Social Science Research 74:77-95.

${ }^{*}$ This paper has benefited from the helpful advice and comments of Malcolm Fairbrother, Neil Fligstein, Daniel Schneider, Dave Harding, Pat Hastings III, Mike Hout, Hilary Hoynes, Maria Abascal, Michelle Jackson, Lane Kenworthy, and Matthew Stimpson. Address: Department of Sociology, Colorado State University, Fort Collins, CO 80523-1784; email: pat.hastings@colostate.edu. 


\title{
Less Equal, Less Trusting? \\ Longitudinal and Cross-sectional Effects of Income Inequality on Trust in U.S. States, 1973-2012
}

\begin{abstract}
Does income inequality reduce social trust? Although both popular and scholarly accounts have argued that income inequality reduces trust, some recent research has been more skeptical, noting these claims are more robust cross-sectionally than longitudinally. Furthermore, although multiple mechanisms have been proposed for why inequality could affect trust, these have rarely been tested explicitly. I examine the effect of state-level income inequality on trust using the 1973-2012 General Social Surveys. I find little evidence that states that have been more unequal over time have less trusting people. There is some evidence that the growth in income inequality is linked with a decrease in trust, but these effects are sensitive to how time is accounted for. While much previous inequality and trust research has focused on status anxiety, this mechanism receives the little support, but mechanisms based on social fractionalization and on exploitation and resentment receive some support. This analysis improves on previous estimates of the effect of state-level inequality on trust by using far more available observations, accounting for more potential individual and state level confounders, and using higher-quality income inequality data based on annual IRS tax returns. It also contributes to our understanding of the mechanism(s) through which inequality may affect trust.
\end{abstract}

Keywords: income inequality; social trust; misanthropy; social fractionalization; status anxiety 


\section{Introduction}

Income inequality in the United States has risen to its highest levels since the Great Depression (Piketty and Saez 2003 [2015]). Many have raised alarm about this trend, suggesting high or rising income inequality has a variety of negative consequences. ${ }^{1}$ A substantial part of the concern has been placed on trust, or the potential lack thereof. Scholars have long proposed that trust is critical to a functional and flourishing society (e.g., Simmel 1950; Lewis and Weigert 1985), and thus the possibility that greater inequality reduces trust is cause for concern.

A substantial number of analyses conducted at the cross-national level report that, on average, more equal countries also have populations that are more trusting of each other (e.g. Bjørnskov 2008; Larsen 2013; Rothstein and Uslaner 2005; Uslaner 2002; Layte 2012). A smaller set of studies have argued for a similar relationship at the level of U.S. States (e.g., Kawachi et al. 1997; Uslaner 2002; Wilkinson and Pickett 2009; Fairbrother and Martin 2013). The stylized "fact" of a negative trust-inequality relationship has been disseminated and asserted widely - even then-sitting President Obama cautioning that:

“...rising inequality... [is] bad for our families and social cohesion-not just because we tend to trust our institutions less, but studies show we actually tend to trust each other less when there's greater inequality."2

However, despite the appearance of a consensus, these existing analyses are limited in a number of respects. First, substantial concerns have been raised about the quality of data on income inequality. Cross-national studies draw upon a handful of different inequality databases that vary widely in quality and oftentimes lead users to radically different conclusions (Ferreira et al. 2015). Similarly, U.S. state-level analyses have relied on Census-based measures of inequality that largely understate top-end inequality and require interpolation in the years between the once-per-decade census, even as other kinds of data become available and their merits increasingly clear (Galbraith and Hale 2008; Piketty and Saez 2003 [2015]; Frank 2014; Chetty et al. 2014; 2017). Second, most of the existing studies (but with the notable exceptions described in this paper) examine only a cross-sectional relationship that makes it difficult to rule out other characteristics of countries or states that might explain why they are both less equal and their populations less trusting. Finally, although every

\footnotetext{
${ }^{1}$ They may also be talking about economic inequality, more broadly. But the research has primarily focused on inequality of income. And in the U.S., income inequality has been a driving factor of other forms of economic inequality (e.g., wealth or consumption inequality) (Piketty 2014; Saez and Zucman 2016).

2"Remarks by the President on Economic Mobility" made on December 4, 2013 (https://www.whitehouse. gov/the-press-office/2013/12/04/remarks-president-economic-mobility).
} 
study posits at least one explanation for why inequality would reduce trust, few studies take multiple explanations into consideration. Here, I advance our understanding of the U.S. state-level relationship between income inequality and trust by (1) presenting analyses that include new waves of individual-level trust data and new high-quality state-level income inequality time-series based on IRS tax returns, and then (2) conducting additional analysis to better understand the plausible mechanisms through which inequality could shape trust.

The paper proceeds as follows: first, I outline three explanations for why income inequality might decrease trust. One possibility is a Social Fractionalization mechanism: because of the human tendency toward homophily, as inequality increases people may interact less often and less effectively with people at different places on the income distribution, leading to decreased trust in others (e.g., Kawachi et al. 1997). Alternatively, a driving factor could be an Exploitation and Resentment mechanism: the rising incomes of those at the very top of the income distribution may generate resentment from those less fortunate. As those at the top pull away, the rest (e.g., "the 99\%") may feel exploited, generating distrust between social classes (e.g., Rothstein and Uslaner 2005). Yet a third possibility is a Status Anxiety mechanism: decreased social trust could be a product of the status anxiety and feelings of relative deprivation that arise from greater income differences between the rich and poor. This argument, rooted in theories of evolutionary development, is that people have different social strategies for social relations in a dominance hierarchy versus an egalitarian society. Rising inequality prompts people to behave in ways more appropriate for a dominance hierarchy in which cooperation and trust are disincentivized (Wilkinson and Pickett 2017).

Next, the I briefly review previous research on inequality and trust, both at the crossnational and state level. In particular, I detail the most rigorous analysis, by far, of inequality and state-level trust presented in Fairbrother and Martin (2013). In contrast to previous studies, they report that while less equal states are indeed less trusting, trust did not decrease more in states that had above-average increases in income inequality. Thus, they discourage interpreting the results as a causal effect of income inequality on trust.

I explain in detail how my research both differs from and advances this research, and I describe the data and methods used to test the inequality-trust relationship. Drawing from the 1973-2012 General Social Survey's linked to state-level administrative data based on IRS tax returns, the decennial Census, and the American Community Survey, I estimate the cross-sectional and longitudinal effects of the state-level Gini index on two measures: a binary measure of trust and six-value trust scale (a reverse-coding of the "misanthropy scale" [Smith 1997]). ${ }^{3}$ In these models, I show that a critical component of the model is how one

\footnotetext{
${ }^{3}$ The effects are "longitudinal" in that they are the effects driven by state-level changes in inequality over time. This usage follows previous work using similar models (e.g., Schmidt-Catran and Fairbrother 2016).
} 
addresses the year variable (or the "secular trend").

In the main models, I find weak evidence that more unequal states have less trusting residents. There is more evidence of a negative longitudinal relationship - a growth in income inequality is associated with a decrease in trust - but these results are sensitive to how time is controlled for. In the analysis of mechanisms, I find some evidence that the results are driven by changes in both very high incomes at the top (supporting Exploitation and Resentment mechanism) and the inequality throughout the rest income distribution (supporting the Social Fractionalization mechanism). I do not find that the inequality-trust relationship is attenuated by controlling for financial satisfaction and perceived relative income, which serve as partial proxies for testing the Status Anxiety mechanism. I conclude by discussing why my results differ substantially from those of Fairbrother and Martin (2013) and outlining how future research may better understand the link between income inequality and trust.

\section{Motivations and Mechanisms}

Trusting others is a fundamental part of society, taking a prominent place in early works on the foundations for social exchange (Simmel 1950) and the collective (Durkheim 1933). Social scientists have reiterated the importance of trust in work on economic markets (e.g., Granovetter 1985; Adler 2001), networks (e.g., Coleman 1988), democracy (e.g., Fukuyama 1995; Warren 1999), neighborhood effects (e.g., Sampson et al. 2002), and social cohesion (e.g., Putnam 2000). Research shows that trust itself has declined in the U.S (Robinson and Jackson 2001; Clark and Eisenstein 2013; Twenge et al. 2014; Putnam 2000) over roughly the same period inequality has increased (Piketty and Saez 2003 [2015]). Could these be causally linked? Below, I present three distinct (though quite possibly overlapping) explanations of why inequality may reduce trust. ${ }^{4}$

\subsection{Social Fractionalization}

Income inequality may affect trust through the restructuring of social life. By definition, higher income inequality means greater differentials across the income distribution. Because personal networks tend to be homogeneous (McPherson, Smith-Lovin, and Cook 2001), social mixing may be reduced by higher income inequality. This would reduce the number of ties that individuals make with others unlike themselves, a process described by Bjørnskov (2008) as "social fractionalization." Social ties are critical for trust itself (e.g., Coleman 1988), and

To be clear, the individual-level observations come repeated cross-sections of respondents in each survey year, so the longitudinal aspect is with respect to the state.

${ }^{4}$ For other reviews of inequality and trust, see Jordahl (2007) and Buttrick and Oishi (2017). 
thus more fractionalization could reduce trust in strangers, as individuals have less incentive to behave in trustworthy ways with those they are less likely to have future interactions with (Coffé and Geys 2006). Furthermore, as the distance grows between people on different parts of the income distribution, the psychological distinction between those in "my group" and outside it becomes increasingly salient, making it harder to identify with and thus trust others (Uslaner 2002).

To be clear, this argument does not necessarily mean people are less disposed towards making connections with others as inequality grows (although this is possible). People tend to trust people similar to themselves, something Fukuyama (1995) describes as one's "trust radius." As inequality increases and the income distribution becomes more spread out, fractionalization occurs and individuals find fewer people within their "trust radius" who they find easy to trust. As a result, social cohesion and trust decline (Bjørnskov 2008; Kawachi et al. 1997). ${ }^{5}$

Finally, increased separation between income groups means that even when individuals interact across income groups, they may more frequently lack the implicit but distinctive assumptions, values, and taken-for-granted knowledge of others. As a result, the interactions may not be as productive as they otherwise could have been (Ridgeway 2014). Lareau (2002) offers an example of this in how working-class parents and children had much less productive visits to the middle-class doctor than did other middle-class parents and children. Reduced social mixing and greater fractionalization not only means fewer cross-group social interactions, but less fruitful ones, which may further reduce trust.

\subsection{Exploitation (by the rich) and Resentment (by the poor)}

An alternative explanation focuses specially on the gaps between the rich and poor. Recent concerns about inequality have emphasized the tensions between the rich and poor. The scholarly story of inequality is punctuated with theories of exploitation-most famously elucidated by Marx (e.g., Marx and Engels 1972) — and episodes of conflict. Even if revolution is not just around the corner, such themes motivated the Occupy and Occupy Wall Street movements, as exemplified in their slogan, "We are the 99\%" (Chomsky 2012). In this account, class conflict produces the distrust.

It is possible that the feelings might not go both ways. For example, the poor might fail to recognize the exploitation of the rich or the rich might be oblivious to the resentment from those less well off. Still, recognition of the feelings in either direction would likely erode

\footnotetext{
${ }^{5}$ Some have referred to this cohesion as "social capital" (e.g., Putnam 2000), but that term has also taken on a wide variety of meanings and a term that is often been more confusing than helpful (see Fischer 2005). Whatever it is called, this cohesion has frequently been operationalized as interpersonal trust.
} 
trust. If people believe those who are relatively (and increasingly) better off are exploiting them, then they are fundamentally less likely to trust them (Gallego 2016). Furthermore, if those at the top of the income distribution recognize the resentment, they may also be wary that the poor will act dishonestly towards them, again reducing trust (Fairbrother and Martin 2013).

\subsection{Status Anxiety}

Another explanation is that decreasing social trust is a product of the status anxiety that arises from greater income differences between the rich and poor. One version of this is articulated by Wilkinson and Pickett (2017). In short, they argue that human beings have evolved with two psychological strategies for social relations. One is based on a dominance hierarchy and the other a more egalitarian society based on reciprocity, cooperation, and trust. Though individuals use both, growing income inequality may shift the balance away from latter and toward the former. This is because income inequality separates people by their position in the income distribution, thereby clarifying and accentuating status differences in income and creating a more hierarchal society.

Veblen ([1899] 1963) noted that status is, in part, reaffirmed through conspicuous consumption. In more unequal contexts, there is a greater tendency to focus on positional goods such as housing (Frank 2007; Fligstein et al. 2017), cars (Bricker et al. 2014), and luxury goods (Walasek and Brown 2015; 2016). As status competition picks up, people's status anxiety and the salience of their status differences relative to others increases. From this, Wilkinson and Pickett $(2009 ; 2017)$ argue that this growing dominance hierarchy results in an environment that rewards those who pursue naked self-interest, rather than one that promotes reciprocity, cooperation, and trust.

\section{Previous Findings}

These theoretical reasons why inequality might reduce trust have spurred a number of empirical examinations of the subject, primarily across countries, but also across states. In an in-depth comparative project, Larsen (2013) showed how inequality has grown and trust declined in the U.S. and U.K., while the opposite trends for both trust and inequality are observed in Sweden and Denmark. Using only a cross-sectional comparison, Bjørnskov (2008) finds the same relationship in over 100 countries in the World Values Survey (WVS), but notes it is driven by relatively rich countries (specifically, the negative relationship is still observed using only the top half of countries in median income, but is not observed using the 
bottom half). Other cross-national studies have shown a similar negative relationship (e.g., Rothstein and Uslaner 2005; Uslaner 2002; Layte 2012). Finally, Fairbrother (2013), using the WVS, shows a longitudinal relationship across countries - in countries where inequality has increased between 1981 and 2008, the populations in those countries also became less trusting, and in the U.S. context Oishi, Kesebir, and Diener (2011) find that trust was lower when the national income inequality was higher.

A few analyses have focused on comparisons of U.S. states. ${ }^{6}$ In a cross-sectional analysis of five years of the GSS, Kawachi et al. (1997) found inverse relationships between state-level income inequality and trust and between trust and mortality rates, and they concluded that a substantial portion of the effect of income inequality on mortality is mediated by trust. Other studies also found a negative association between income inequality and trust using an aggregate time series of the United States (Uslaner 2002) and in another cross-sectional analysis of U.S. states (e.g., Wilkinson and Pickett 2009).

However, the most thorough analysis of inequality and trust in the U.S. context is provided by Fairbrother and Martin (2013). Following previous research on income inequality and trust, they analyze the effects of Gini index, which is defined as the average difference between all pairs of proportional income in the population, ranging from 0 (if everyone had the same income) to 1 (if one household had all the income). However, Fairbrother and Martin go beyond the standard approaches by separating out the average level of inequality in each state from the over-time variation within states by subtracting each state-year Gini from that state's over-time average (a technique described in greater detail below). They find a significant negative effect of the cross-sectional measure of state-level inequality, but no effect from the longitudinal measure. In other words, they find less equal states are indeed less trusting, but trust did not decrease more in states that had above-average increases in income inequality. In further checks, they also found no evidence of a longitudinal effect using a 10-year lagged measure of income inequality on trust or with the level of inequality for the respondent's state at age 16, nor did they find any effects of county-level inequality (cross-sectional or longitudinal). From this, they suggest caution in accepting a causal trust and inequality relationship.

With the exception of Fairbrother and Martin (2013), the studies reviewed here all conclude that inequality negatively effects trust. But these studies differ in their explanation, drawing from the theories of social fractionalization, exploitation and resentment, and status anxiety that were presented above. In the next section, I describe how I use Fairbrother and Martin's analysis as a starting point and comparison for my own analysis, and then further

\footnotetext{
${ }^{6}$ For examples of non-U.S. within-country inequality-trust studies, see work by Coffé and Geys (2006) and Leigh (2006).
} 
explore how to disentangle the mechanisms.

\section{The Present Study}

In the first part of my analysis, I advance the study conducted by Fairbrother and Martin (2013) with three important improvements. First, their analysis ended with 2004 data, so my analysis (up to 2012) includes 4 more survey waves with over 6,900 additional observations (a $27 \%$ increase), as well as a greater variation in income inequality because inequality grew to even higher levels within states between 2004 and 2012. Second, my analysis includes a much larger number of individual and state level controls that could confound the relationship between income inequality and trust. Finally, my analysis uses income inequality data from a new annual series based on IRS tax returns (Frank 2014). Previous state-level Gini measures, including those of Fairbrother and Martin (2013), are based on the decennial Census with, at best, model-based interpolation (using payroll and employment for a set of sectors within states) to fill in the data between years (Galbraith and Hale 2008).

I show that by implementing these three improvements I obtain substantially different results from the same multilevel models that follow Fairbrother and Martin's approach of separating out the cross-sectional and longitudinal differences in inequality.

In addition to the single measure of trust, I use the misanthropy scale (Smith 1997) which has also been used as a measure of general trust (e.g., Twenge et al. 2014; Simpson 2006). Fairbrother and Martin reported that models using this outcome had similar results. I examine this. Using both outcomes, I also show the sensitivity of the results to how time is (or is not) controlled for, and I discuss the costs and promises of each approach. No previous study of inequality and trust examines this crucial specification, which I show can lead to widely differing conclusions.

In the second section, I present analysis using alternative measures of inequality that provide suggestive evidence of the mechanisms behind the findings. Research shows that while inequality has grown across the income distribution, it has been particularly accentuated at the very top (Piketty and Saez 2003 [2015]; Kenworthy 2017). If the Social Fractionalization mechanism is a key to the explaining the trend, we should see stronger results when using measures that capture inequality across the income distribution. On the other hand, if the Exploitation and Resentment mechanism is key, then the effect should largely be driven by the growth in income near the very top (i.e., top income shares). In their analysis of how income inequality affects mobility, Chetty et al. (2014) provide a way of separating these effects: they decompose the Gini index into inequality coming from the upper tail and the rest of the income distribution by defining the "Bottom $99 \%$ Gini" as the overall Gini index 
minus the top $1 \%$ income share. This decomposition allows me to separately assess the effect of top-end inequality from the inequality in the rest of the distribution.

Finally, if a negative effect of inequality on trust is about increased status anxiety, then we would expect to be able to attenuate the relationship by controlling for it. Status anxiety is largely about how people think others see and evaluate them (e.g., Delhey and Dragolov 2014; Layte and Whelan 2014; Paskov et al. 2017). Unfortunately, the dataset for this paper has no direct measures of this, but I seek to partially infer it with two measures. First, I use a measure of financial satisfaction. Conceptually, if two people of the same income have different levels of financial satisfaction, it is plausible that the one reporting less satisfaction is more concerned about their status than the other. Second, I use a measure of how people perceive their income relative to others. Again, conceptually if two people with the same income in fact perceive their relative income differently, the one with lower perceived relative income likely has greater status anxiety. The models in this analysis do not literally only compare people of the same income, but they control for income, which allows for the comparison as though income were constant. Of course, status is more than just economic standing, but to the extent that financial satisfaction and perceived relative income partially proxy for status anxiety (with household income controlled for), then the effect of income inequality on trust should attenuate when those measures are added to the models.

It is possible that multiple explanations are valid. For example, people could suffer from status anxiety while also resenting the rich while also living in a more fractionalized society. The aim of this part of the analysis is not to pick one dominant explanation, but to determine the extent to which each explanation is supported.

\section{$5 \quad$ Data and Methods}

\subsection{General Social Survey}

The individual-level data come from the nationally-representative General Social Survey (GSS) which has been conducted annually or biannually since 1972 with response rates greater than 70\% (Smith et al. 2013). In addition to its high quality, it is the only longrunning nationally representative survey to measure trust. The restricted-access GSS geographic identification file contains state identifiers for every survey year beginning with 1973, with which I match each respondent to a variety of state-level measures. ${ }^{7}$ Beginning

\footnotetext{
${ }^{7}$ Data from the GSS, Census, and ACS are available from the respective websites of each. The inequality data based on IRS tax returns are available at http://www.shsu.edu/eco_mwf/inequality.html. However, the GSS state-level identifiers can only be obtained through special contractual arrangements with NORC: http://gss.norc.org/documents/other/ObtainingGSSSensitiveDataFiles.pdf
} 
in 2006, the GSS moved to a panel format, where respondents were reinterviewed in up to two additional waves. In the analyses presented here, I do not include re-interviews, but including them yields similar results. In all, I analyze 31,857 observations in 909 state-years from $1973-2012 .^{8}$

\subsubsection{Outcomes}

Social trust is measured by asking:

- "Generally speaking, would you say that most people can be trusted or that you can't be too careful in life?" [codebook item: trust]

Four percent of respondents said, "it depends," which I included with "you can't be too careful," but excluding those yielded similar results. This question has been used extensively in studies of trust, but some have raised concerns that this single item can be interpreted as the related concept of "caution" and that combining it with of two other items better captures one's general trust toward others (Simpson 2006). These other items are measured by asking:

- "Do you think most people would try to take advantage of you if they got a chance, or would they try to be fair?" [fair]

- "Would you say that most of the time people try to be helpful, or that they are mostly just looking out for themselves?" [helpful]

Together, these three questions are used to make up the "misanthropy scale" (Smith 1997). To create this scale I follow the standard coding that places "it depends" at the midpoint of the other two possible responses to each question. Thus, the response to each question has a value of 2 (= doubts others are trusting, fair, or helpful), 1 (= it depends) or 0 (= believes others are generally trusting, fair, or helpful). I sum these together to create a single scale from $0-6$, which has the advantage of providing additional variation in one's level of trust compared the the binary trust measure above. ${ }^{9}$ Finally, to make the direction of my effects consistent with the binary trust outcome, I reverse code the misanthropy scale and call it

\footnotetext{
${ }^{8}$ Fairbrother and Martin (2013) report results that exclude District of Columbia. I include DC, which is not so much of an outlier in the IRS-based data. Regardless, I find the results do not substantively differ by excluding DC respondents from the analysis.

${ }^{9}$ The misanthropy scale has a Cronbach's alpha of .67, which is lower than generally preferred levels (Nunnally 1978; Lance, Butts, and Michels 2006). However, as noted in text, the purpose of using the scale is because each question that is part of it may capture a different aspect of general trust (Smith 1997; Simpson 2006). For this reason, it should not necessarily be expected for all the items to be highly correlated.
} 
the "trust scale." An analysis of recent panel data finds that both the trust item itself and the scale have a high degree of reliability in repeated measurements (Hout and Hastings 2016). Figure 1 shows that trust - as measured by either outcome variable - has declined substantially between 1973 and 2012 .

Figure 1: Trust in Others from 1973-2012 (Source: General Social Survey)

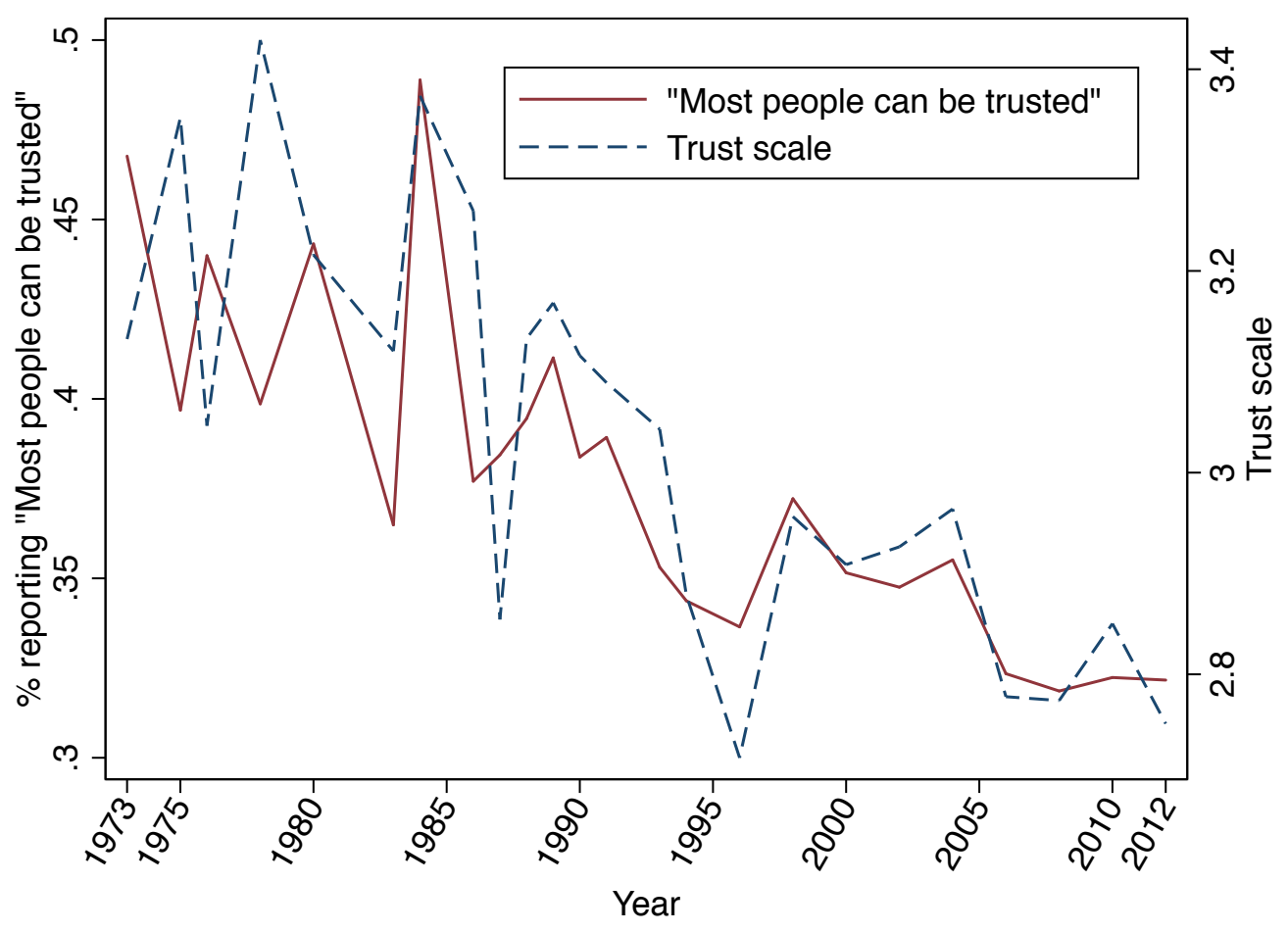

\subsubsection{Individual-level Independent Variables}

In the models that test for whether the inequality-trust relationship is attenuated by controlling for partial proxies of status anxiety, I add continuous measures of two GSS questions:

- "We are interested in how people are getting along financially these days. So far as you and your family are concerned, would you say that you are pretty well satisfied with your present financial situation, more or less satisfied, or not satisfied at all?" [satfin] (coded 1-3)

- "Compared with American families in general, would you say your family income is far below average, below average, average, above average, or far above average?" [finrela] (coded 1-5) 
In all of my analyses, I control for a number of individual level variables that could bias the relationship between income inequality and trust. I control for income, which is measured by asking respondents to place their family's income into an income bin. The bins have changed over time, but the GSS includes a harmonized "best estimate" by assigning each respondent the midpoint of their income bin, except for the open-ended top income bin where incomes were assigned using a Pareto curve (Ligon [1989] 1994; Hout 2004). I control for a logged income measure, although additional analysis using multiple income bins revealed similar results.

I control for race/ethnicity using a four-item coding: non-Hispanic white, non-Hispanic black, other non-Hispanic, and Hispanic. The GSS did not measure Hispanic or Latino ethnicity until 2000, so for observations before that year I use country of ancestral origin. This correlates extremely well with self-identified Hispanic from 2000 onward and has been used in previous research on race and ethnicity (Hout and Goldstein 1994). Previous research finds that racial and ethnic groups report different average levels of trust (Simpson et al. 2007; Smith 2010; Abascal and Baldassarri 2015), although in additional analyses I found that the effect of income inequality on trust did not vary significantly by race or ethnicity.

Trust itself follows a lifecycle, so I control for age and age-squared (Robinson and Jackson 2001; Clark and Eisenstein 2013). I control for religious service attendance (from $0=$ never attend to $8=$ attend more than once a week), as religious service attendance is a associated with trust (Daniels and von der Ruhr 2010; Dingemans and Ingen 2015). Finally, I control for a number of sociodemographic characteristics: sex, years of education (using highest degree earned made no change to the main findings), marital status (= married, widowed, divorced, separated, or never married), number of children in the household, and number of adults in the household.

\subsection{Area Level Data}

\subsubsection{Income inequality}

The paper focuses on state-level inequality. In theory, it is not readily apparent what is the appropriate unit of aggregation to measure income inequality in order to expect to observe an effect on trust. Unfortunately, there is no equivalent IRS-based annual inequality data for units smaller than states (e.g., counties). Furthermore, the GSS geo-coded data only has location identifiers below the state beginning in 1993, making it impossible to examine the effect of inequality during the first 20 years of the survey for smaller levels. ${ }^{10}$

\footnotetext{
${ }^{10}$ Fairbrother and Martin (2013) conducted a county-level analysis on a subsample of the GSS data and found no effect with Census-based inequality data.
} 
My primary inequality measure is the state-level Gini index, which assesses inequality across the entire income distribution, which is constructed from data published in the IRS's Statistics of Income and made available by Frank (2014). This is the first study I am aware of to use these IRS-based data to examine the relationship between inequality and trust. Previous studies have primarily used state-level inequality measures provided by the decennial Census, although state-level inequality measures can also be obtained from the Current Population Survey (CPS) and the American Community Survey (ACS) (after 2005) (Stone et al. 2016). However, the IRS data has several advantages. First, the IRS data are based on the full population, whereas Census inequality is based on the long form census (which went to about one in six households). Similar measures from the CPS and ACS are based on even far smaller samples. Second, the Census was only collected each decade with linear or model-based interpolation between years (Galbraith and Hale 2008), while the IRS data are annual. Third, the other data sources rely on self-reported data where lower-income respondents are likely to over-report income and higher-income respondents are likely to under-report income (Akhand and Liu 2002). Of course, the IRS is the only data source that penalizes respondents for their income reporting errors. Fourth, the other data sources are subjected to more top-coding of income, and as a result, the Ginis based on the IRS data are substantially larger (i.e., show more inequality) than those reported by the Census or CPS because they better account for high-income households (Richard et al. 2009). A possible limitation of IRS-based data is that it risks censoring households whose income is below the threshold for mandatory tax filing. However, these households may still file taxes to receive a refund or to benefit from tax credits.

The same data series also includes a calculation of the top income shares, which some scholars have preferred (e.g., Piketty and Saez 2003 [2015]). In a recent paper, Chetty et al. (2014) subtracted the top $1 \%$ income share from the overall Gini index. The decomposition separates the inequality coming from the upper tail and the rest of the income distributionthe latter they define as the "Bottom 99\% Gini" - and it allows me to separate the effect of top-end inequality from the inequality throughout the rest of the distribution. 
Figure 2: 90th, 50th, and 10th Percentiles of Income Inequality Across States from 1973-2012 (Source: Frank 2014)
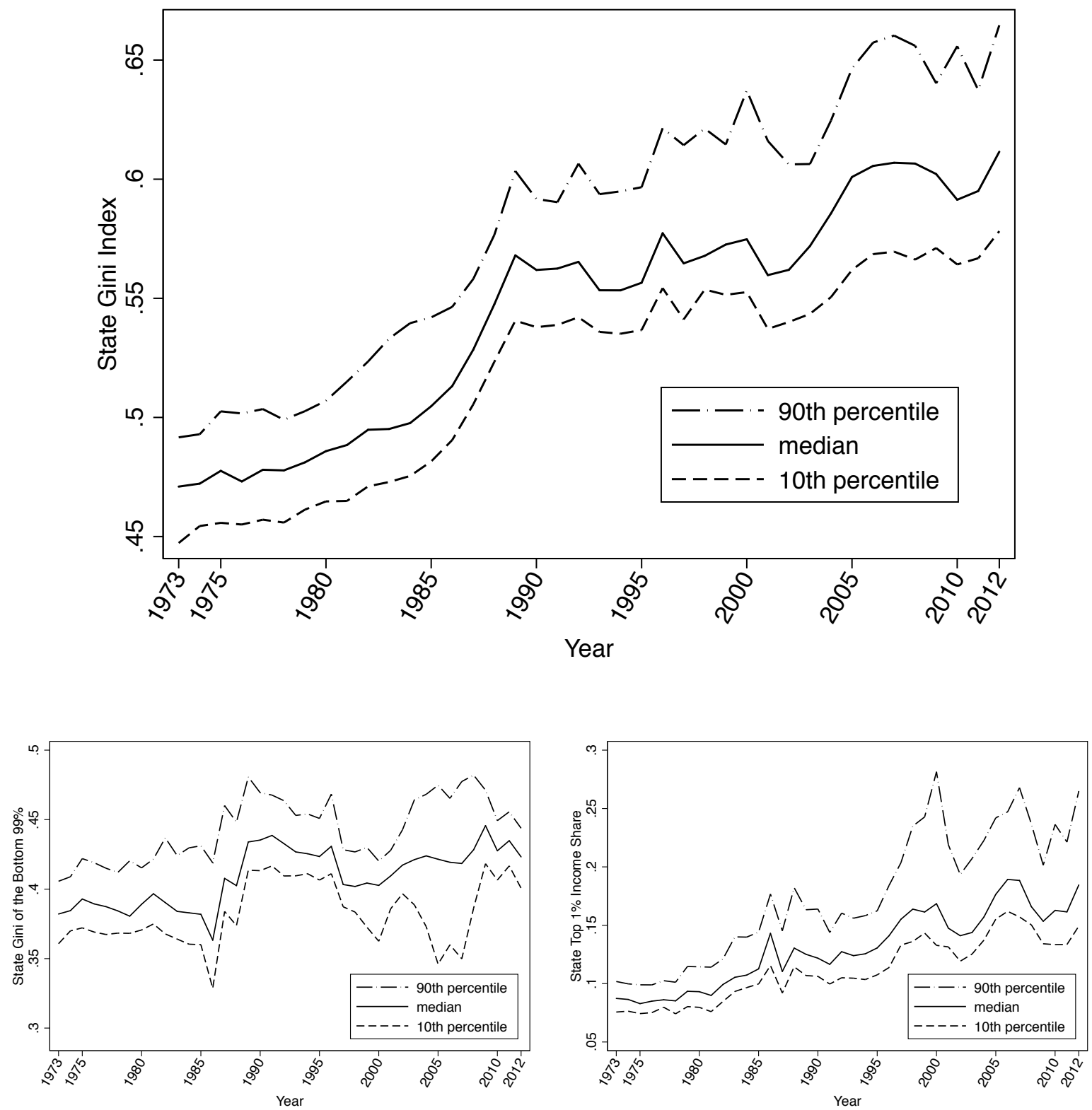

The top panel of Figure 2 shows the state-level Gini index across states during the analysis period. Two trends are notable. First, consistent with other accounts of income inequality, inequality grew considerably over the period of study. In fact, the Gini of the least equal state in 1973 (.50 in the District of Columbia) was lower than the most equal state in 2012 (.55 in West Virginia). Second, the gap between the $10^{\text {th }}$ and $90^{\text {th }}$ percentiles is nearly twice as large in 2012 as 1973, meaning that inequality grew faster in some states than others. It is this variation that will be used to assess the effect of inequality on trust. The two bottom 
panels of Figure 2 show the same trends for the Top 1\% Income Share and the Bottom $99 \%$ Gini. Both show substantial variation over time. Although both grew, the increase of the Bottom $99 \%$ Gini was substantially more modest than the growth of the Top $1 \%$ Income Share, whose median nearly doubled between 1973 and 2012.

\subsubsection{Other state level data}

At the state level I control for state-level income per capita (but using logged median household income - which is less sensitive to high incomes - produced nearly identical results). Racial and ethnic diversity may also affect trust (e.g., Putnam 2007; Stolle et al. 2008; but see Abascal and Baldassarri 2015), so I include measures of \% black and \% foreign born. Hispanic or Latino ethnicity was not consistently recorded in the census until 1980 and is not included, but the changing trends should be largely captured in $\%$ foreign born. I account for population shifts and growth by controlling for state population density (logged), and I include a southern state indicator variable, as previous research has found that Southerners are, on average, less trusting than non-Southerners (Simpson 2006). These state-level controls are the same as those used by Fairbrother and Martin (2013) except for the inclusion of $\%$ foreign born.

Table 1: Descriptives

\begin{tabular}{lccccc}
\hline & mean & sd & min & max & count \\
\hline Trust (binary) & 0.38 & & 0 & 1 & 31857 \\
Trust (scale) & 3.05 & 2.23 & 0 & 6 & 29457 \\
Between State Gini & 0.55 & 0.03 & .48 & 0.70 & 31857 \\
Within State Gini & 0.00 & 0.05 & -.11 & 0.15 & 31857 \\
Between State Top 1\% share (SD) & 0.00 & 0.50 & -.88 & 2.95 & 31857 \\
Within State Top 1\% share (SD) & -0.00 & 0.87 & -2.1 & 3.25 & 31857 \\
Between State Gini 99\% (SD) & 0.00 & 0.56 & -.97 & 3.68 & 31857 \\
Within State Gini 99\% (SD) & -0.00 & 0.83 & -2.9 & 3.89 & 31857 \\
Financial satisfaction & 2.04 & 0.74 & 1 & 3 & 30586 \\
Perceived relative income & 2.91 & 0.84 & 1 & 5 & 30465 \\
Log(income) & 10.76 & 0.98 & 6.2 & 12.6 & 31857 \\
Female & 0.53 & & 0 & 1 & 31857 \\
Age (years) & 43.87 & 16.54 & 18 & 89 & 31857 \\
(Age x Age)/100 & 21.98 & 16.12 & 3.2 & 79.2 & 31857 \\
Non-Hispanic white & 0.78 & & 0 & 1 & 31857 \\
Non-Hispanic black & 0.12 & & 0 & 1 & 31857 \\
Non-Hispanic other & 0.03 & & 0 & 1 & 31857 \\
Hispanic & 0.07 & & 0 & 1 & 31857 \\
Married & 0.62 & & 0 & 1 & 31857 \\
Widowed & 0.06 & & 0 & 1 & 31857 \\
Divorced & 0.10 & & 0 & 1 & 31857 \\
Separated & 0.03 & & 0 & 1 & 31857 \\
\hline & continued on next page & & &
\end{tabular}


Table 1 - continued from previous page

\begin{tabular}{lrrrrr}
\hline Never married & 0.20 & & 0 & 1 & 31857 \\
Number of adults & 2.22 & 0.91 & 1 & 8 & 31857 \\
Number of children & 1.96 & 1.78 & 0 & 8 & 31857 \\
Religious service attendance & 3.81 & 2.69 & 0 & 8 & 31857 \\
Years of education & 12.87 & 3.07 & 0 & 20 & 31857 \\
Urban & 0.60 & & 0 & 1 & 31857 \\
Suburban & 0.27 & & 0 & 1 & 31857 \\
Rural & 0.13 & & 0 & 1 & 31857 \\
State income/capita & 25.03 & 5.48 & 13 & 54.2 & 31857 \\
State percent foreign born & 0.08 & 0.07 & .007 & 0.27 & 31857 \\
State population density (logged) & 4.97 & 0.99 & .017 & 9.28 & 31857 \\
State percent black & 0.13 & 0.08 & .0023 & 0.71 & 31857 \\
Southern state & 0.35 & & 0 & 1 & 31857 \\
\hline
\end{tabular}

Standard errors in parentheses

${ }^{*} p<.05,{ }^{* *} p<.01,{ }^{* * *} p<.001$

Notes: Descriptives are weighted to account for sampling. Individual level data come from the General Social Survey 1973-2012. State level data come from the Census (1970, 1980, 1990, 2000), American Community Survey (2006-2012), and IRS Statistics of Income (1973-2012).

Table 1 presents descriptives of all individual and state-level measures. There is no missing state-level data. At the individual level, listwise deletion of missing data on income removes $9.8 \%$ of the cases, while missing data on the remaining controls removes another $1.2 \%$ of the data. The mean Gini was nearly identical between those in the final sample and with those not in the sample (.55 for those in vs .57 for those not). Respondents in the sample were slightly more trusting ( $38 \%$ vs $32 \%$ were trusting by the binary trust variable; 3.05 vs 2.84 by the trust scale). It is possible that the willingness to report sensitive personal information such as income might depend on the level of one's general trust in others, which could in turn be affected by inequality. If anything, then, missing data could slightly underestimate the effect of income inequality on trust. But, to put this in context, a standard deviation of the trust scale is 2.23 (see Table 1), meaning the difference between those in and not in the sample $(3.05-2.84=2.11)$ is less than a tenth of a standard deviation.

\subsection{Analytical Strategy}

\subsubsection{Main models}

I employ a multilevel modeling strategy that allows for the simultaneous but separate estimation of cross-sectional and longitudinal relationships. The key feature of this model, used also by Fairbrother and Martin (2013), is to decompose and separately enter the mean of inequality for each state (the "between" or "cross-sectional" portion) and the deviations in each state-year from the state mean (the "within" or "longitudinal" portion). Denoting the states by $s$ and years by $t$, I define: 


$$
\begin{aligned}
G i n i_{\text {Between }} & =\overline{\text { Gini }_{s t}} \\
\text { Gini_Within }_{\text {st }} & =\text { Gini }_{\text {st }}-\overline{\text { Gini }_{s t}}
\end{aligned}
$$

and estimate the effect of both measures with a random effects model (also known as a multilevel, mixed, or hierarchical linear model). Comparisons with and advantages of this approach over fixed effects models are discussed extensively in Raudenbush and Bryk (2002), Bell and Jones (2015), and Fairbrother (2013). However, I also estimated supplemental models with state fixed effects which are presented in the Appendix. Models with state fixed effects can only show the within-state change (because the Gini_between is $_{s}$ controlled away), but the estimated effect of Gini_within $n_{s t}$ is nearly identical between the random effects and fixed effects models.

For the binary trust outcome, I use a logit specification. Formally, the individual-level model is:

$$
\begin{aligned}
\operatorname{Ln}\left(\frac{\text { Trust }_{\text {ist }}}{1-\text { Trust }_{\text {ist }}}\right)= & \beta_{0}+\beta_{1} \text { Gini_Within }_{\text {st }}+\beta_{2} \text { Gini_Between }_{s} \\
& +\beta_{3} \text { Individual_covariates }_{\text {ist }}+\beta_{4} \text { State_covariates }_{\text {st }} \\
& +\left[\beta_{5} \text { Time }_{t}\right]+\zeta_{s}+\zeta_{s t}+\epsilon_{\text {ist }}
\end{aligned}
$$

where $\beta_{3}$ and $\beta_{4}$ denote vectors of all individual and state-level controls, and $\zeta_{s}$ and $\zeta_{s t}$ denote random state and state-year effects. This approach accounts in the standard errors for the non-independence of observations within shared contexts without needing post-hoc clustering adjustments (Schmidt-Catran and Fairbrother 2016). For analysis with the continuous trust scale as the outcome, the entire left hand side of equation (3) is simply replaced with Trust_scale ${ }_{\text {ist. }}{ }^{11}$ Because the outcome is the trust of the respondent at the moment of completing the survey, I use level of income inequality from the survey year. It is possible, however, that respondents take some time to "update" their perceptions, so for robustness I also estimated models that lagged inequality by a year and I found substantively identical results.

$\beta_{5}$ is in brackets to denote that I consider and present three ways of accounting for time, which have substantial consequences for the estimate of the Gini_Within ${ }_{s t}$ coefficient. First, I estimate a model without any time controls. This approach utilizes the entire growth of

\footnotetext{
${ }^{11}$ Models were estimated in Stata 14.2 with the melogit and mixed commands using the sampling weights provided by the GSS.
} 
income inequality over time shown in Figure 2. Using the full variation in inequality allows for a more efficient estimate, but the approach may fail to account for other aspects that were changing in the U.S. between 1973 and 2012 besides the level of income inequality. Already, the most likely time-varying confounders are controlled for at the state level: changes in income per capita, population density, percent black, and percent foreign born. However, another omitted variable could still be factor.

Another approach that I estimate is to account for a possible "secular trend" by adding a linear year term as a control. Both inequality and trust follow roughly linear trends upward and downward, respectively, and the linear term nets out these trends. This parsimonious approach controls for the linear version of any unobserved confounding variables, and is the model implemented by Fairbrother and Martin (2013).

Finally, the most conservative approach that I estimate is to include year fixed effects (an indicator variable for every year). This approach controls for all aggregate trends. Any national level factors or shifts that could change state-level inequality and trust are accounted for. But this approach also nets out the average level of inequality for each year, forcing the estimate to be based exclusively on changes in income inequality within states net of the overall changes of income inequality across states. By presenting all three time specifications, I am able to compare how sensitive the results are to these different approaches.

\subsubsection{Testing the mechanisms}

In the second part of my analysis, I estimate three sets of additional models in order to better understand the mechanisms. First, I present models that examine the effects of inequality measured by the Top 1\% Income Share and Bottom 99\% Gini. This allows for the comparison of the effects of the right-tail inequality of the top 1\% (which is key to the Exploitation and Resentment mechanism) and the inequality spread out through the rest of population (which is key to the Social Fractionalization mechanism). Then, I estimate models adding additional the controls for financial satisfaction and perceived relative income. If the Status Anxiety mechanism is key to explaining the decrease in trust, then the effect of inequality should attenuate once these partial proxies for it are accounted for.

\section{Results}

\subsection{Main results}

The full models that examine the effect of income inequality on the binary trust measure and the continuous trust scale are presented in Tables 2 and 3. To visualize and more easily 
compare the key results, the income inequality coefficients are also presented in a coefficient plot in Figure 3. Note that logistic regression coefficients (including those in multilevel models such as those presented here) cannot be precisely compared across models because the coefficients are sensitive to differing amounts of unobserved heterogeneity between models (Mood 2010). Multilevel linear probability models of the binary trust outcome produced substantively identical conclusions, and, of course, the trust scale models are not subject to this limitation. 
Table 2: Coefficients (in Log Odds) from Models of Trust in Others (binary measure)

\begin{tabular}{|c|c|c|c|c|c|c|}
\hline \multirow[b]{2}{*}{ Between State Gini } & \multicolumn{2}{|c|}{$\begin{array}{l}(1) \\
\text { No time control }\end{array}$} & \multicolumn{2}{|c|}{$\begin{array}{c}(2) \\
\text { Year linear control }\end{array}$} & \multicolumn{2}{|c|}{$\begin{array}{c}(3) \\
\text { Year fixed effects }\end{array}$} \\
\hline & -2.40 & $(1.55)$ & -1.09 & $(1.38)$ & -0.41 & $(1.50)$ \\
\hline Within State Gini & $-4.45^{* * *}$ & $(0.57)$ & $-1.26^{*}$ & $(0.62)$ & 0.017 & $(0.99)$ \\
\hline $\log ($ income $)$ & $0.21^{* * *}$ & $(0.019)$ & $0.21^{* * *}$ & $(0.019)$ & $0.21^{* * *}$ & $(0.019)$ \\
\hline Female & $-0.10^{* *}$ & $(0.032)$ & $-0.10^{* *}$ & $(0.032)$ & $-0.11^{* * *}$ & $(0.032)$ \\
\hline Age (years) & $0.043^{* * *}$ & $(0.0053)$ & $0.043^{* * *}$ & $(0.0053)$ & $0.043^{* * *}$ & $(0.0053)$ \\
\hline$($ Age x Age $) / 100$ & $-0.025^{* * *}$ & $(0.0053)$ & $-0.025^{* * *}$ & $(0.0054)$ & $-0.025^{* * *}$ & $(0.0054)$ \\
\hline Non-Hispanic white & 0 & $()$. & 0 & $()$. & 0 & $()$. \\
\hline Non-Hispanic black & $-1.06^{* * *}$ & $(0.083)$ & $-1.05^{* * *}$ & $(0.083)$ & $-1.07^{* * *}$ & $(0.083)$ \\
\hline Non-Hispanic other & $-0.51^{* * *}$ & $(0.066)$ & $-0.50^{* * *}$ & $(0.067)$ & $-0.51^{* * *}$ & $(0.068)$ \\
\hline Hispanic & $-0.51^{* * *}$ & $(0.061)$ & $-0.50^{* * *}$ & $(0.060)$ & $-0.51^{* * *}$ & $(0.060)$ \\
\hline Married & 0 & $()$. & 0 & $()$. & 0 & $()$. \\
\hline Widowed & -0.10 & $(0.064)$ & -0.10 & $(0.063)$ & -0.10 & $(0.062)$ \\
\hline Divorced & $-0.14^{* *}$ & $(0.047)$ & $-0.13^{* *}$ & $(0.047)$ & $-0.13^{* *}$ & $(0.047)$ \\
\hline Separated & $-0.24^{* *}$ & $(0.077)$ & $-0.24^{* *}$ & $(0.078)$ & $-0.24^{* *}$ & $(0.079)$ \\
\hline Never Married & 0.052 & $(0.051)$ & 0.058 & $(0.051)$ & 0.055 & $(0.051)$ \\
\hline Num of adults & -0.020 & $(0.017)$ & -0.021 & $(0.017)$ & -0.022 & $(0.017)$ \\
\hline Num of children & -0.0053 & $(0.0075)$ & -0.0056 & $(0.0076)$ & -0.0053 & $(0.0075)$ \\
\hline Religious service attendance & $0.027^{* * *}$ & $(0.0071)$ & $0.026^{* * *}$ & $(0.0071)$ & $0.026^{* * *}$ & $(0.0071)$ \\
\hline Years of education & $0.17^{* * *}$ & $(0.0066)$ & $0.17^{* * *}$ & $(0.0067)$ & $0.17^{* * *}$ & $(0.0067)$ \\
\hline Urban & 0 & $()$. & 0 & $()$. & 0 & $()$. \\
\hline Suburban & -0.042 & $(0.037)$ & -0.040 & $(0.037)$ & -0.045 & $(0.037)$ \\
\hline Rural & 0.021 & $(0.063)$ & 0.032 & $(0.062)$ & 0.032 & $(0.060)$ \\
\hline State income/capita & -0.0069 & $(0.0059)$ & 0.0080 & $(0.0065)$ & 0.0074 & $(0.0086)$ \\
\hline State percent foreign born & 0.065 & $(0.67)$ & 0.22 & $(0.60)$ & 0.29 & $(0.62)$ \\
\hline State pop. density (log) & -0.027 & $(0.042)$ & -0.056 & $(0.042)$ & -0.051 & $(0.042)$ \\
\hline State percent black & -0.82 & $(0.60)$ & -0.76 & $(0.56)$ & -0.86 & $(0.55)$ \\
\hline Southern state & $-0.33^{* *}$ & $(0.11)$ & $-0.29^{* *}$ & $(0.10)$ & $-0.28^{* *}$ & $(0.10)$ \\
\hline Year (linear) & & & $-0.022^{* * *}$ & $(0.0038)$ & & \\
\hline Year fixed effects & No & & No & & Yes & \\
\hline Constant & $-4.20^{* * *}$ & $(0.98)$ & $38.4^{* * *}$ & $(7.41)$ & $-4.94^{* * *}$ & $(0.89)$ \\
\hline $\operatorname{var}($ State $)$ & $0.031^{*}$ & $(0.012)$ & $0.026^{*}$ & $(0.011)$ & $0.029^{*}$ & $(0.012)$ \\
\hline $\operatorname{var}($ State-year) & $0.041^{* * *}$ & $(0.0088)$ & $0.033^{* * *}$ & $(0.0077)$ & 0.010 & $(0.0073)$ \\
\hline Observations & 1857 & & 31857 & & 31857 & \\
\hline
\end{tabular}

Standard errors in parentheses

${ }^{*} p<.05,{ }^{* *} p<.01,{ }^{* * *} p<.001$

Note: Models from multilevel mixed-effects logistic regression. Non-Hispanic white, Married, and Urban are reference categories of categorical variables. 
Table 3: Coefficients from Models of Trust Scale

\begin{tabular}{|c|c|c|c|c|c|c|}
\hline \multirow[b]{2}{*}{ Between State Gini } & \multicolumn{2}{|c|}{$\stackrel{(1)}{\text { No time control }}$} & \multicolumn{2}{|c|}{$\begin{array}{c}(2) \\
\text { Year linear control }\end{array}$} & \multicolumn{2}{|c|}{$\begin{array}{c}(3) \\
\text { Year fixed effects }\end{array}$} \\
\hline & -2.61 & $(1.52)$ & -1.81 & $(1.43)$ & -1.07 & $(1.50)$ \\
\hline Within State Gini & $-4.39^{* * *}$ & $(0.47)$ & $-2.32^{* * *}$ & $(0.61)$ & -1.11 & $(0.92)$ \\
\hline $\log ($ income $)$ & $0.21^{* * *}$ & $(0.013)$ & $0.21^{* * *}$ & $(0.013)$ & $0.21^{* * *}$ & $(0.014)$ \\
\hline Female & $0.17^{* * *}$ & $(0.026)$ & $0.17^{* * *}$ & $(0.026)$ & $0.16^{* * *}$ & $(0.026)$ \\
\hline Age (years) & $0.042^{* * *}$ & $(0.0040)$ & $0.042^{* * *}$ & $(0.0040)$ & $0.043^{* * *}$ & $(0.0040)$ \\
\hline$($ Age x Age) $/ 100$ & $-0.016^{* * *}$ & $(0.0041)$ & $-0.016^{* * *}$ & $(0.0041)$ & $-0.017^{* * *}$ & $(0.0040)$ \\
\hline Non-Hispanic white & 0 & $()$. & 0 & (.) & 0 & (.) \\
\hline Non-Hispanic black & $-1.05^{* * *}$ & $(0.079)$ & $-1.05^{* * *}$ & $(0.079)$ & $-1.06^{* * *}$ & $(0.077)$ \\
\hline Non-Hispanic other & $-0.37^{* * *}$ & $(0.085)$ & $-0.37^{* * *}$ & $(0.087)$ & $-0.38^{* * *}$ & $(0.090)$ \\
\hline Hispanic & $-0.49^{* * *}$ & $(0.069)$ & $-0.48^{* * *}$ & $(0.068)$ & $-0.48^{* * *}$ & $(0.067)$ \\
\hline Married & 0 & (.) & 0 & (.) & 0 & (.) \\
\hline Widowed & $-0.13^{*}$ & $(0.055)$ & $-0.14^{*}$ & $(0.055)$ & $-0.13^{*}$ & $(0.054)$ \\
\hline Divorced & $-0.25^{* * *}$ & $(0.030)$ & $-0.24^{* * *}$ & $(0.030)$ & $-0.24^{* * *}$ & $(0.030)$ \\
\hline Separated & $-0.26^{* * *}$ & $(0.063)$ & $-0.26^{* * *}$ & $(0.063)$ & $-0.26^{* * *}$ & $(0.064)$ \\
\hline Never Married & $0.11^{*}$ & $(0.046)$ & $0.11^{*}$ & $(0.046)$ & $0.11^{*}$ & $(0.045)$ \\
\hline Num of adults & -0.020 & $(0.015)$ & -0.020 & $(0.015)$ & -0.021 & $(0.015)$ \\
\hline Num of children & 0.0047 & $(0.0084)$ & 0.0046 & $(0.0084)$ & 0.0047 & $(0.0083)$ \\
\hline Religious service attendance & $0.056^{* * *}$ & $(0.0070)$ & $0.055^{* * *}$ & $(0.0069)$ & $0.055^{* * *}$ & $(0.0069)$ \\
\hline Years of education & $0.17^{* * *}$ & $(0.0053)$ & $0.17^{* * *}$ & $(0.0054)$ & $0.17^{* * *}$ & $(0.0055)$ \\
\hline Urban & 0 & $()$. & 0 & $()$. & 0 & $()$. \\
\hline Suburban & -0.050 & $(0.042)$ & -0.048 & $(0.043)$ & -0.054 & $(0.043)$ \\
\hline Rural & 0.087 & $(0.061)$ & 0.093 & $(0.061)$ & 0.090 & $(0.059)$ \\
\hline State income/capita & 0.0027 & $(0.0052)$ & $0.013^{*}$ & $(0.0064)$ & 0.015 & $(0.0091)$ \\
\hline State percent foreign born & -0.20 & $(0.73)$ & -0.029 & $(0.72)$ & -0.21 & $(0.74)$ \\
\hline State pop. density (log) & -0.037 & $(0.042)$ & -0.060 & $(0.041)$ & -0.061 & $(0.039)$ \\
\hline State percent black & -0.63 & $(0.64)$ & -0.59 & $(0.60)$ & -0.61 & $(0.58)$ \\
\hline Southern state & $-0.38^{* * *}$ & $(0.10)$ & $-0.34^{* * *}$ & $(0.095)$ & $-0.34^{* * *}$ & $(0.095)$ \\
\hline Year (linear) & & & $-0.014^{* * *}$ & $(0.0031)$ & & \\
\hline Year fixed effects & No & & No & & Yes & \\
\hline Constant & -1.08 & $(0.95)$ & $26.9^{* * *}$ & $(6.06)$ & $-1.91^{*}$ & $(0.90)$ \\
\hline $\operatorname{var}($ State $)$ & $0.035^{* * *}$ & $(0.012)$ & $0.030^{* * *}$ & $(0.011)$ & $0.031^{* * *}$ & $(0.011)$ \\
\hline var(State-year) & $0.053^{* * *}$ & $(0.0091)$ & $0.051^{* * *}$ & $(0.0090)$ & $0.031^{* * *}$ & $(0.010)$ \\
\hline $\operatorname{var}($ Residual $)$ & $4.02^{* * *}$ & $(0.033)$ & $4.02^{* * *}$ & $(0.033)$ & $4.03^{* * *}$ & $(0.033)$ \\
\hline Observations & 29457 & & 29457 & & 29457 & \\
\hline
\end{tabular}

Standard errors in parentheses

${ }^{*} p<.05,{ }^{* *} p<.01,{ }^{* * *} p<.001$

Note: Models from multilevel mixed-effects linear regression. Non-Hispanic white, Married, and Urban are reference categories of categorical variables. 
Figure 3: Coefficient Plots of Main Models with Different Year Controls. Error bars show 95\% confidence intervals; ticks show $90 \%$ confidence intervals.

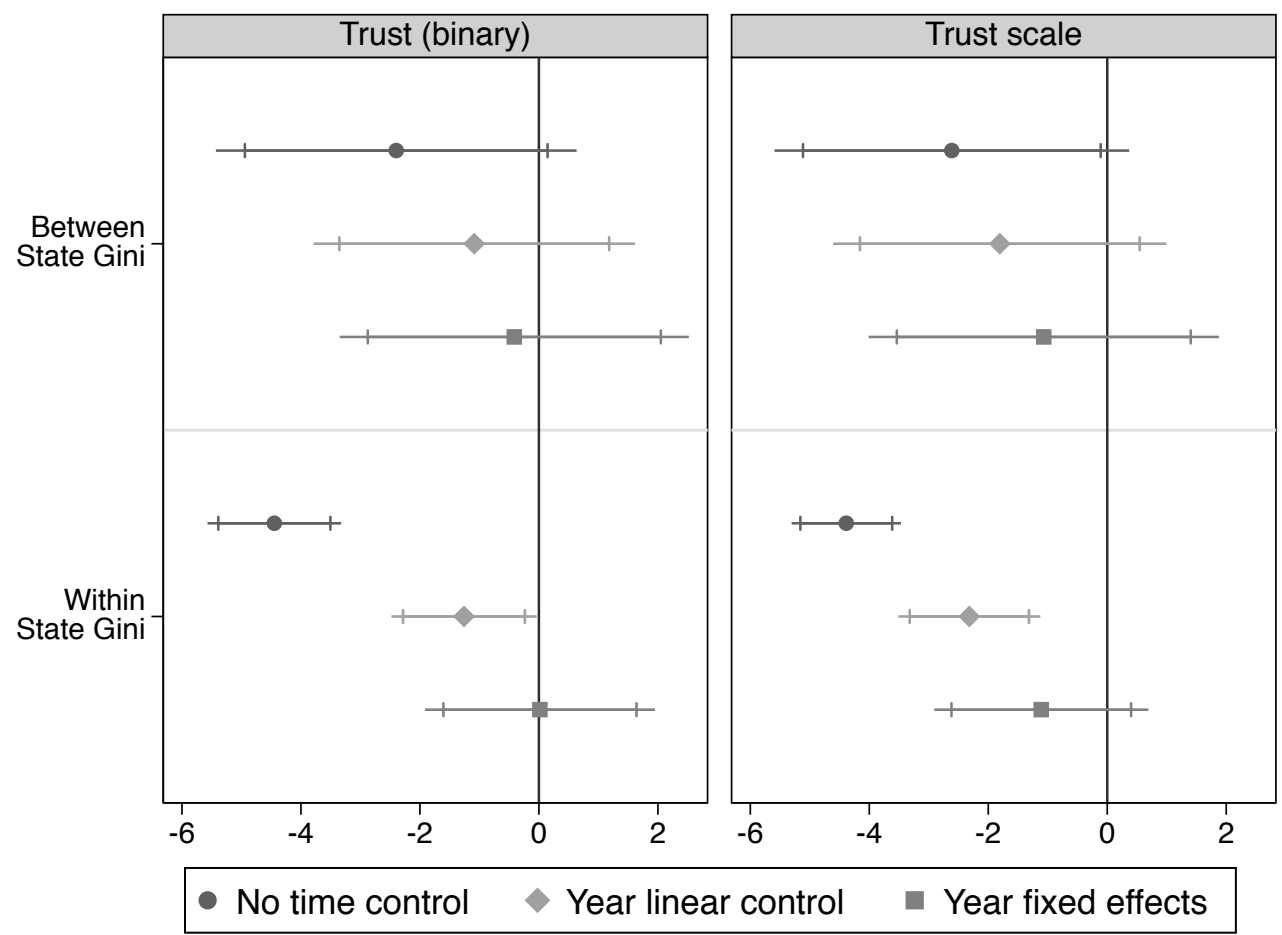

In all six models, the between-state coefficient is negative, but non-significant. Contrary to previous cross-sectional studies, as well as the findings of Fairbrother and Martin (2013), there is little evidence that states with higher levels of income inequality have lower levels of trust. ${ }^{12}$

In contrast to the null findings of the between-state effect, there is some evidence of a within-state effect. In the multilevel logit models, the effect is negative and large with no time control (Model 1). This is consistent with the descriptive pattern that - net of individuallevel characteristics and other observed time-varying state measures - trust decreased where inequality increased. With a year trend (Model 2), the preferred model of Fairbrother and Martin (2013), the effect of within-state inequality is much smaller, but remains statistically significant. For example, a 0.1 increase in the Gini within a state would predict a $[1$ $e^{(-1.26 * .1)}=$ ] $11 \%$ decrease in the probability a respondent would believe most people can be trusted. However, once the more conservative year fixed effects are applied, this betweenstate coefficient is nearly zero and not significant.

\footnotetext{
${ }^{12}$ One might be surprised that the cross-sectional between estimate would vary at all by the inclusion of time controls. This is a compositional issue. Although the between-state Gini is constant for each state, not every state appears in the GSS in every year, and states that appear more often in later years than early years have higher average levels of inequality. The time controls adjust for this too.
} 
The same trend is observed in the multilevel models of the trust scale. Again the coefficients are negative and statistically significant in Models 1 and 2. In the latter model a 0.1 increase in the Gini within a state would predict a 0.23 decrease in trust on the 6-point scale. The within-state Gini is not significant once year fixed effects are included. Note, however, that for both sets of models the addition of year fixed effects does not only reduce the effect size, but also expands the standard errors (likely because there is less variation in inequality from which to derive the estimate). For example, in Model 3 from the trust scale model, the magnitude of the within-state Gini is more than double the standard error from Model 1 (in other words, the Model 3 coefficient would be statistically significant if it had the certainty of Model 1).

\subsection{Mechanisms}

To test the Social Fractionalization and the Exploitation and Resentment mechanisms, I next present models that show the effects of the Top 1\% Income Share and Bottom $99 \%$ Gini. As before, I separate out the cross-sectional (between state) and longitudinal (within state) effects. The inequality coefficients are plotted in Figure 4 (tables of the full results are in the Appendix). For clarity in comparing the coefficients of the two inequality measures, I standardized $($ mean $=0$, standard deviation $=1$ ) both the Top $1 \%$ Income Share and Bottom 99\% Gini before decomposing them into the within and between state measures. 
Figure 4: Coefficient Plots of Models with Alternative Inequality Measures. Error bars show 95\% confidence intervals; ticks show $90 \%$ confidence intervals.

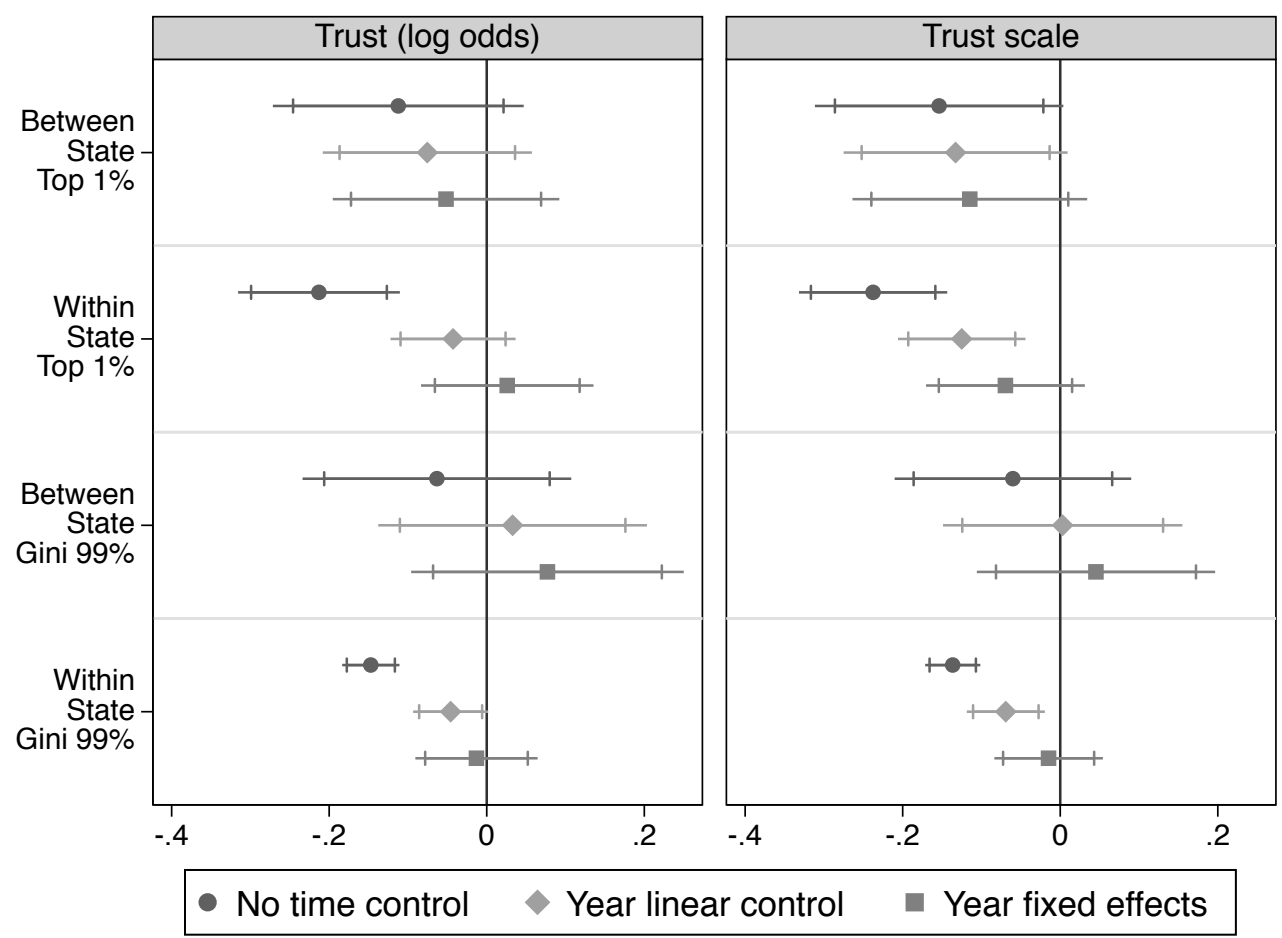

For both measures, the patterns are fairly similar, both to each other and to the effect of the Gini in the main results. At the top of the figure are the coefficients for the Top 1\% Income Share. The between-state effect of the Top 1\% Income Share is consistently negative but, at best, marginally significant $(\mathrm{p}<.1)$ in the trust-scale models with no time control or the linear year measure. The within-state effect of the Top 1\% Income Share is negative in both models without time controls and the trust-scale model with a year linear term. For example, in this latter model, a one-standard deviation increase in the Top 1\% Income Share within a state is associated with a 0.13 decrease on the trust scale.

The between-state effect of the Bottom 99\% Gini is close to zero and non-significant, but the within-state effect of the Bottom $99 \%$ Gini is negative and significant in the models without time or with a year linear control (but at $\mathrm{p}<.1$ in the case of binary trust outcome). Using the same model above, a one-standard deviation increase in the Bottom $99 \%$ gini within a state is associated with a 0.07 decrease in trust.

These results suggest that the negative (but non-statistically-significant) coefficient of the between-state Gini found in the main models of Tables 2 and 3 is largely driven by states with higher top $1 \%$ income shares. However, our interest is particularly in the within-state effect. There is some evidence of a causal relationship between trust and changes in both the Top 
1\% Income Share and Bottom 99\% Gini, but these effects almost entirely disappear in the most conservative models with year fixed effects. Thus, there is no clear evidence that either type of inequality - the extreme pulling away of the rich (which would be consistent with the Exploitation and Resentment mechanism) or the inequality in the rest of the population (which would be consistent with the Social Fractionalization mechanism) - is driving the results from the main models.

To test the Status Anxiety mechanism, I reestimate the main models while controlling for financial satisfaction and perceived relative income. I present models with the key coefficients in Tables 4 and 5 (and the full models are in the Appendix). Because some cases had missing data on at least one of the two new controls, I also reran the main models using the same subsample. These are shown in Models 1, 3, and 5 (with no time control, year linear term, and year fixed effects, respectively), and the models with the new controls are in Models 2 , 4 , and 6 (with the same time controls).

Table 4: Coefficients (Log Odds) from Trust Models Controlling for Financial Satisfaction and Perceived Relative Income

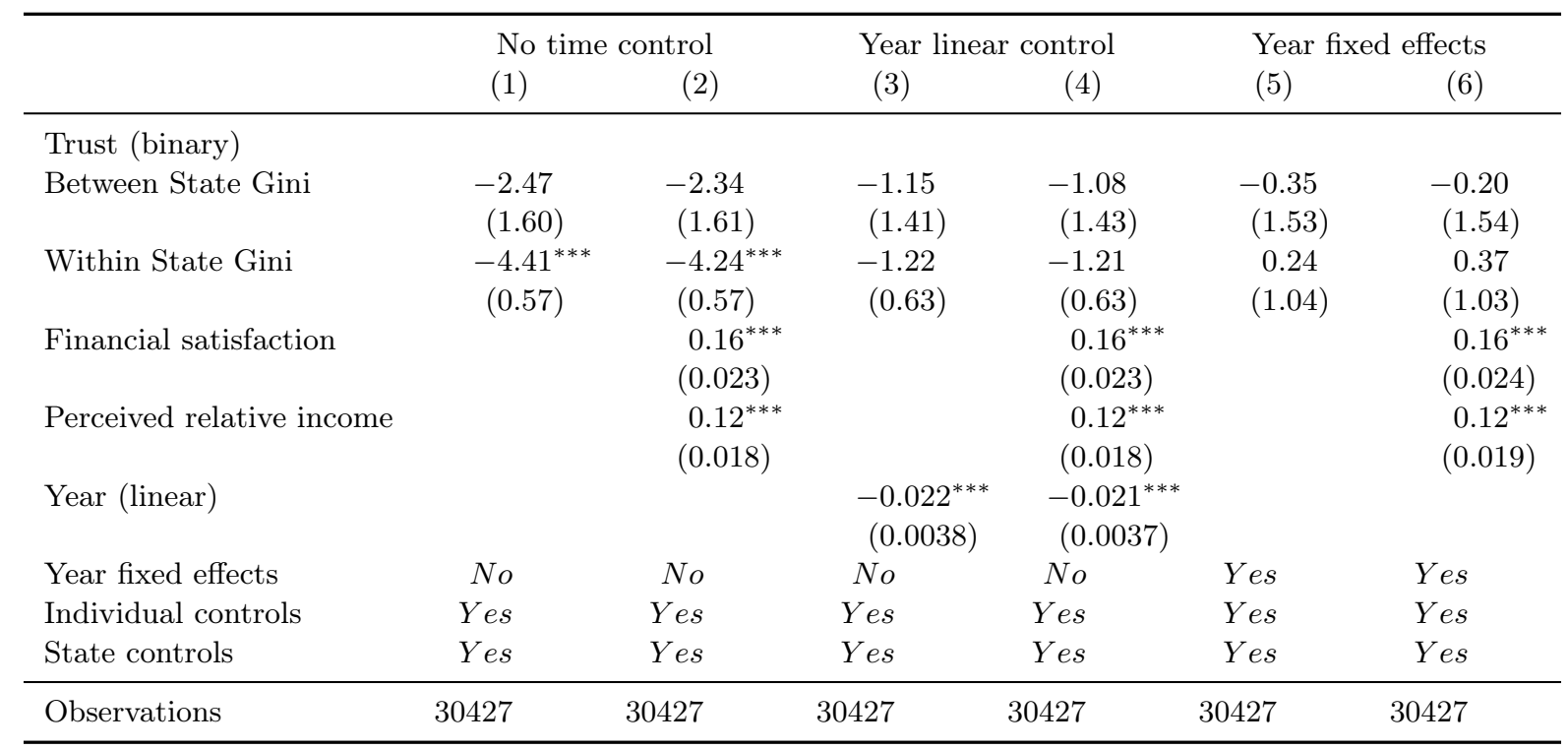

Standard errors in parentheses

${ }^{*} p<.05,{ }^{* *} p<.01,{ }^{* * *} p<.001$

Note: Models 1, 3, and 5 include the same variables as Table 2's Models 1, 2, and 3. Models 2, 4 and 6 , add controls for financial satisfaction and perceived relative income. 
Table 5: Coefficients from Trust-Scale Models Controlling for Financial Satisfaction and Perceived Relative Income

\begin{tabular}{|c|c|c|c|c|c|c|}
\hline & \multicolumn{2}{|c|}{ No time control } & \multicolumn{2}{|c|}{ Year linear control } & \multicolumn{2}{|c|}{ Year fixed effects } \\
\hline & (1) & $(2)$ & $(3)$ & $(4)$ & $(5)$ & $(6)$ \\
\hline \multicolumn{7}{|l|}{ Trust (scale) } \\
\hline Between State Gini & $\begin{array}{c}-2.68 \\
(1.52)\end{array}$ & $\begin{array}{c}-2.48 \\
(1.55)\end{array}$ & $\begin{array}{c}-1.89 \\
(1.43)\end{array}$ & $\begin{array}{c}-1.76 \\
(1.47)\end{array}$ & $\begin{array}{c}-1.10 \\
(1.51)\end{array}$ & $\begin{array}{c}-0.88 \\
(1.55)\end{array}$ \\
\hline Within State Gini & $\begin{array}{c}-4.39^{* * *} \\
(0.47)\end{array}$ & $\begin{array}{c}-4.13^{* * *} \\
(0.46)\end{array}$ & $\begin{array}{c}-2.35^{* * *} \\
(0.61)\end{array}$ & $\begin{array}{c}-2.29^{* * *} \\
(0.60)\end{array}$ & $\begin{array}{c}-1.08 \\
(0.93)\end{array}$ & $\begin{array}{c}-0.90 \\
(0.95)\end{array}$ \\
\hline Financial satisfaction & & $\begin{array}{c}0.25^{* * *} \\
(0.024)\end{array}$ & & $\begin{array}{c}0.25^{* * *} \\
(0.025)\end{array}$ & & $\begin{array}{c}0.25^{* * *} \\
(0.025)\end{array}$ \\
\hline Perceived relative income & & $\begin{array}{c}0.12^{* * *} \\
(0.018)\end{array}$ & & $\begin{array}{l}0.12^{* * *} \\
(0.018)\end{array}$ & & $\begin{array}{c}0.12^{* * *} \\
(0.018)\end{array}$ \\
\hline Year (linear) & & & $\begin{array}{c}-0.014^{* * *} \\
(0.0031)\end{array}$ & $\begin{array}{c}-0.013^{* * *} \\
(0.0030)\end{array}$ & & \\
\hline Year fixed effects & No & No & No & No & Yes & Yes \\
\hline Individual controls & Yes & Yes & Yes & Yes & Yes & Yes \\
\hline State controls & Yes & Yes & Yes & Yes & Yes & Yes \\
\hline Observations & 29275 & 29275 & 29275 & 29275 & 29275 & 29275 \\
\hline
\end{tabular}

Standard errors in parentheses

${ }^{*} p<.05,{ }^{* *} p<.01,{ }^{* * *} p<.001$

Note: Models 1, 3, and 5 include the same variables as Table 3's Models 1, 2, and 3. Models 2, 4 and

6 , add controls for financial satisfaction and perceived relative income.

If financial satisfaction and perceived relative income are partial proxies of status anxiety, the mechanism would suggest the inequality coefficients should attenuate once controlling for them. This does not happen. Although financial satisfaction and perceived relative income are both positively associated with trust, they barely reduce the inequality coefficients. ${ }^{13}$ These models suggest that inequality does not reduce trust because inequality increases people's status anxiety. ${ }^{14}$

\footnotetext{
${ }^{13}$ I also considered a self-ranking of social position measure [GSS codebook item: rank] as another partial proxy of status anxiety. Unfortunately, this question was only asked to a subsample of the respondents, and only overlapped with respondents asked the trust question in 5 survey years, shrinking the sample to $<5000$ and reducing the variation in state-level income inequality. Social rank is positively associated with trust, but controlling for social rank - either by itself or in combination with financial satisfaction and perceived relative income - does not attenuate the inequality coefficients.

${ }^{14}$ This is effectively a test of mediation. To control for the possibility that the effect of inequality on trust is mediated by status anxiety, it may be necessary to include an interaction term, or else the model assumes there is no interaction between the cause (income inequality) and the mediators (financial satisfaction and perceived relative income) (VanderWeele and Vansteelandt 2009). I find similar results for the other coefficients with and without interaction terms.
} 


\section{Discussion and Conclusion}

This paper finds little evidence that cross-sectional state-level inequality (the between-state effect) is associated with less trust. That is, states that have been more unequal over time do not necessarily have less trusting people. There is some evidence, however, that the growth in income inequality (the within-state effect) is associated with a decrease in trust. However, these longitudinal effects are much weaker when year fixed effects are included.

I do not take a strong position on which time control is the "best." The more conservative the approach, the less likely that there are unobserved confounders biasing the results, but the more true variation in inequality that is also netted out. In the most conservative model, the year fixed effects net out most of the growth in inequality that we are precisely interested in understanding the effect of. If some other trending characteristics are driving the main longitudinal, within-state results, these unidentified characteristics would have to operate independently of the other time-varying state-level controls and independent of even a year time trend.

Future work may benefit from focusing more on the change itself. One possibility is that once a particular level of inequality becomes normalized in the long run, it has much less effect than inequality which is rapidly changing in the short run (Hirschman and Rothschild 1973; Esping-Andersen and Nedoluzhko 2017). It is particularly plausible that abrupt inequality changes have different effects than more stable (even high) inequality with respect to psychological outcomes, including social trust. One recent panel study found no difference in life satisfaction between times of persistently high or persistently low inequality, but did find that individual were less satisfied in those years where inequality was higher than during a typical year (Schröder 2016). On the other hand, others have argued that rapidly rising inequality can be interpreted as a sign of future upward mobility, which might explain why income inequality appears to be correlated positively with life satisfaction in some developing economies (Cheung 2016) and correlated less negatively with life satisfaction in America than in Europe (Alesina et al. 2004). Future research might, for example, explore the effect on social trust of the $\%$ change in income inequality from some previous year.

My findings also differ substantially from those reported by Fairbrother and Martin (2013), who - using the year time trend specification - found a strong negative cross-sectional inequality effect and absolutely no longitudinal effect. What explains the differences? To explore this, I conducted a supplemental analysis in which I first began with their model (I was able to obtain nearly, but not exactly, the same coefficients) and then iteratively changed parts to make it more like mine. I found two critical differences:

First, my inequality measure is based on annual IRS tax returns, instead of voluntarily 
self-reported income from a sample of Census respondents. Merely replacing their model with the IRS data series makes the cross-sectional effect go away entirely. For reasons specified in the data section above, I believe the tax return data are better, and tax-based data have become the staple of economic research (e.g., Chetty et al. 2014; 2017; Piketty 2014; Piketty and Saez 2003 [2015]; Saez and Zucman 2016). Unfortunately, to date, no one has provided a thorough consistent comparison of the two state-level inequality measures. Second, I find that the addition of state \% foreign born substantially reduces the cross-sectional effect in the Fairbrother and Martin (2013) model. Given the income differences between racial and ethnic groups, it is unsurprising that $\%$ foreign born is correlated with inequality. As reviewed above, there is a contentious debate on the possible relationship between diversity and trust. Once this is accounted for, even the results based on Census inequality data are weakened to the point of being non-significant. ${ }^{15}$

This paper also presented two different but popular measures of trust - the binary trust question and the trust scale (the reverse-coded misanthropy scale). Both gave similar results, although the evidence in favor of a negative relationship is slightly stronger using the scale measure.

The results of the analysis of mechanisms are inconclusive, but provide a jumping off point for future research. While one popular and highly cited component of the inequality-trust literature has focused the Status Anxiety mechanism, this mechanism received little support. Controlling for measures of financial satisfaction and relative deprivation had almost no mediating effect in my analysis. As discussed already, these two measures are far from ideal proxies of status anxiety, which is far more broadly conceived as how people think others see and evaluate them (e.g., Delhey and Dragolov 2014; Layte and Whelan 2014; Paskov et al. 2017). It is possible the proxies insufficiently measure true feelings of status anxiety, and that this accounts for the lack of change in the inequality coefficients. Future work, likely relying on different datasets, will hopefully be able to better match these concepts and measures.

In contrast, the Social Fractionalization mechanism and Exploitation and Resentment mechanism both received some support. In some of the models, the results are consistent with an effect driven by top income shares (as measured by the Top 1\% Income share) and an effect driven by income inequality throughout the distribution (as measured by the Bottom $99 \%$ Gini). However, much more work is needed to understand these mechanisms. For example, future studies could investigate how income inequality is related to social fractionalization. This mechanism suggests networks should be more homophilous as inequality increases and

\footnotetext{
${ }^{15}$ I am very grateful to Malcolm Fairbrother for corresponding with me about the analysis in Fairbrother and Martin (2013) and my own analysis.
} 
people interact less often and less effectively with people at different places on the income distribution, but this should be examined empirically. This mechanism is also consistent with research suggesting rising economic inequality in the U.S. has increased economic residential segregation (Mayer 2002; Reardon and Bischoff 2011). But neighborhoods represent only one dimension of where widening stratification based on income may occur.

Similarly, to understand the Exploitation and Resentment mechanism, researchers need better measures of these feelings. McCall $(2013 ; 2016)$ provides the best research on what people think about the rich, especially as it relates to inequality, but unfortunately, these respondent attitudes were only measured in a few more recent waves of the GSS. Now that these concerns have moved more to the forefront, future studies will undoubtedly measure these important attitudes and provide more data to analyze.

Taking a step in the other direction, it is also important for research to study if and how trust itself is the pathway between income inequality and many important social problems. In fact, this work finds that the relationship between inequality and trust is not especially large. As such, if there is a "net effect" of income inequality on outcomes of interest, these results suggest that trust - despite being a prominently discussed pathway - may not have a great deal of explanatory power. At minimum, researchers should not solely focus on trust. And more generally, this study underlies the importance of considering multiple mechanisms in seeking to understand the consequences of income inequality (Neckerman and Torche 2007; Moss et al. 2013). Doing so is an important step towards effectively evaluating and addressing the broader potential consequences of income inequality. 


\section{References}

Abascal, Maria and Delia Baldassarri. 2015. "Love Thy Neighbor? Ethnoracial Diversity and Trust Reexamined." American Journal of Sociology 121(3):722-782.

Adler, Paul S. 2001. "Market, Hierarchy, and Trust: The Knowledge Economy and the Future of Capitalism." Organization Science 12(2):214-234.

Akhand, Hafiz and Haoming Liu. 2002. "Income Inequality in the United States: What the Individual Tax Files Say." Applied Economics Letters 9(4):255-259.

Alesina, Alberto, Rafael Di Tella, and Robert MacCulloch. 2004. "Inequality and happiness: Are Europeans and Americans different?" Journal of Public Economics 88:2009-2042.

Bell, Andrew and Kevin Jones. 2015. "Explaining Fixed Effects: Random Effects Modeling of Time-Series Cross-Sectional and Panel Data." Political Science Research and Methods $3(1): 133-153$.

Bjørnskov, Christian. 2008. "Social Trust and Fractionalization: A Possible Reinterpretation." European Sociological Review 24(3):271-283.

Bricker, Jesse, Rodney Ramcharan, and Jacob Krimmel. 2014. "Signaling Status: The Impact of Relative Income on Household Consumption and Financial Decisions." Finance and Economics Discussion Series 2014-76. Board of Governors of the Federal Reserve System (U.S.).

Buttrick, Nicholas R. and Shigehiro Oishi. 2017. "The Psychological Consequences of Income Inequality." Social and Personality Psychology Compass 11(3):1-12.

Chetty, Raj, David Grusky, Maximilian Hell, Nathaniel Hendren, Robert Manduca, and Jimmy Narang. 2017. "The Fading American Dream: Trends in Absolute Income Mobility Since 1940." Science 356(6336):398-406.

Chetty, Raj, Nathaniel Hendren, Patrick Kline, and Emmanuel Saez. 2014. "Where Is the Land of Opportunity? The Geography of Intergenerational Mobility in the United States." Quarterly Journal of Economics 129(4):1553-1623.

Cheung, Felix. 2016. "Can Income Inequality Be Associated with Positive Outcomes? Hope Mediates the Positive Inequality-Happiness Link in Rural China." Social Psychological and Personality Science 7(4):320-330.

Chomsky, Noam. 2012. Occupy. Brooklyn: Zuccotti Park Press.

Clark, April K. and Marie A. Eisenstein. 2013. "Interpersonal Trust: An Age-Period-Cohort Analysis Revisited." Social Science Research 42:361-375.

Coffé, Hilda and Benny Geys. 2006. "Community Heterogeneity: A Burden for the Creation of Social Capital?" Social Science Quarterly 87(5):1053-72. 
Coleman, James S. 1988. "Social Capital in the Creation of Human Capital." American Journal of Sociology 94:S95-S121.

Daniels, Joseph P. and Marc von der Ruhr. 2010. "Trust in others: Does religion matter?" Review of Social Economy 68(2):163-186.

Delhey, Jan and Georgi Dragolov. 2014. "Why Inequality Makes Europeans Less Happy: The Role of Distrust, Status Anxiety, and Perceived Conflict." European Sociological Review 30(2):151-165.

Dingemans, Ellen and Erik Van Ingen. 2015. "Does Religion Breed Trust? A cross-national study of the effects of religious involvement, religious faith and religious context on social trust." Journal for the Scientific Study of Religion 54(4):739-755.

Durkheim, Emile. 1933. The Division of Labor in Society. New York: Free Press.

Esping-Andersen, Gøsta and Lesia Nedoluzhko. 2017. "Inequality equilibria and individual well-being." Social Science Research 62:24-28.

Fairbrother, Malcolm. 2013. "Two Multilevel Modeling Techniques for Analyzing Comparative Longitudinal Survey Datasets." Political Science Research and Methods 2(1):119-140.

Fairbrother, Malcolm and Isaac Martin. 2013. "Does Inequality Erode Social Trust? Results from Multilevel Models of US States and Counties." Social Science Research 42:347-360.

Ferreira, Francisco H. G., Nora Lustig, and Daniel Teles. 2015. "Appraising Cross-National Income Inequality Databases: An Introduction." The Journal of Economic Inequality 13 (4):497-526.

Fischer, Claude. 2005. "Bowling Alone: What's the Score?" Social Networks 27(2):155-167.

Fligstein, Neil, Orestes P. Hastings, and Adam Goldstein. 2017. "Keeping up with the Joneses: How Households Fared in the Era of High Income Inequality and the Housing Price Bubble, 1999-2007." Socius: Sociological Research for a Dynamic World 3:1-15.

Frank, Mark. 2014. "A New State-Level Panel of Annual Inequality Measures over the Period 1916-2005." Journal of Business Strategies 31(1):241-263.

Frank, Robert. 2007. Falling Behind: How Rising Inequality Harms the Middle Class. University of California Press.

Fukuyama, Francis. 1995. Trust: The Social Virtues and Creation of Prosperity. London: Hamish Hamilton.

Galbraith, James and Travis J. Hale. 2008. "State Income Inequality and Presidential Election Turnout and Outcomes." Social Science Quarterly 89(4):887-901.

Gallego, Aina. 2016. "Inequality and the Erosion of Trust Among the Poor: Experimental Evidence." Socio-Economic Review 14(3):443-460. 
Granovetter, Mark. 1985. "Economic Action and Social Structure: The Problem of Embeddedness." American Journal of Sociology 91(3):481-510.

Hirschman, Albert O. and Michael Rothschild. 1973. "The Changing Tolerance for Income Inequality in the Course of Economic Development." The Quarterly Journal of Economics $87: 544-566$.

Hout, Michael. 2004. "Getting the Most out of the GSS Income Measures." GSS Methodological Report 101.

Hout, Michael and Joshua Goldstein. 1994. "How 4.5 Million Irish Immigrants Came to Be 41 Million Irish Americans: Demographic, Social, and Subjective Components of the Ethnic Composition of the White Population of the United States." American Sociological Review 59:64-82.

Hout, Michael and Orestes P. Hastings. 2016. "Reliability of the Core Items in the General Social Survey: Estimates from the Three-Wave Panels, 2006-2014." Sociological Science 3:971-1002.

Jordahl, Henrik. 2007. "Inequality and Trust." IFN Working Paper No 715.

Kawachi, Ichiro, Bruce Kennedy, Kimberly Lochner, and Deborah Prothrow-Stith. 1997. "Social Capital, Income Inequality, and Mortality." American Journal of Public Health 87:1491-1498.

Kenworthy, Lane. 2017. "Why the Surge in Income Inequality?" Comptemporary Sociology $46(1): 1-9$.

Lance, Charles E., Marcus M. Butts, and Lawrence C. Michels. 2006. "The Sources of Four Commonly Reported Cutoff Criteria: What Did They Really Say?" Organizational Research Methods 9(2):202-220.

Lareau, Annette. 2002. "Invisible Inequality: Social Class and Childrearing in Black Families and White Families." American Sociological Review 67(5):747-776.

Larsen, Christian Albrekt. 2013. The Rise and Fall of Social Cohesion: The Construction and De-Construction of Social Trust in the US, UK, Sweden and Denmark. Oxford: Oxford University Press.

Layte, Richard. 2012. "The Association Between Income Inequality and Mental Health: Testing Status Anxiety, Social Capital, and Neo-Materialist Explanations." European Sociological Review 28(4):498-511.

Layte, Richard and Christopher Whelan. 2014. "Who Feels Inferior? A Test of the Status Anxiety Hypothesis of Social Inequalities in Health." European Sociological Review 30 (4):525-535.

Leigh, Andrew. 2006. "Trust, Inequality and Ethnic Heterogeneity." Economic Record 82 (258):268-280. 
Lewis, J. David and Andrew Weigert. 1985. "Trust As a Social Reality." Social Forces 63 (4):967-985.

Ligon, Ethan. [1989] 1994. "The Development and Use of a Consistent Income Measure for the General Social Survey." GSS Methodological Report 64.

Marx, Karl and Friedrich Engels. 1972. The Marx-Engels Reader. Edited by Robert C. Tucker. New York: Norton.

Mayer, Susan. 2002. "How Economic Segregation Affects Children's Educational Attainment." Social Forces 8(1):153-176.

McCall, Leslie. 2013. The Undeserving Rich: American Beliefs About Inequality, Opportunity, and Redistribution. New York: Cambridge University Press.

McCall, Leslie. 2016. "Political and Policy Responses to Problems of Inequality and Opportunity: Past, Present, and Future." In The Dynamics of Opportunity in America, edited by I. Kirsch and H. Braun, pp. 415-42. New York: Springer.

McPherson, Miller, Lynn Smith-Lovin, and James Cook. 2001. "Birds of a Feather: Homophily in Social Networks." Annual Review of Sociology 27:415-444.

Mood, Carina. 2010. "Logistic Regression: Why We Cannot Do What We Think We Can Do, and What We Can Do About It." European Sociological Review 26(1):67-82.

Moss, David, Anant Thaker, and Howard Rudnick. 2013. "Inequality and Decision Making: Imagining a New Line of Inquiry." Harvard Business School Working Paper 13-099.

Neckerman, Kathryn and Florencia Torche. 2007. "Inequality: Causes and Consequences." Annual Review of Sociology 33:335-357.

Nunnally, Jum C. 1978. Psychometric Theory. New York: McGraw-Hill, 2nd edition.

Oishi, Shigehiro, Selin Kesebir, and Ed Diener. 2011. "Income Inequality and Happiness." Psychological Science 22(9):1095-1100.

Paskov, Marii, Klarita Gërxhani, and G. Van de Werfhorst Herman. 2017. "Giving up on the Joneses? the Relationship Between Income Inequality and Status-Seeking." European Sociological Review 33(1):112-123.

Piketty, Thomas. 2014. Capital in the Twenty-First Century. Boston, MA: Harvard University Press.

Piketty, Thomas and Emmanuel Saez. 2003 [2015]. "Income Inequality in the United States, 1913-1998." Quarterly Journal of Economics 118(1):1-39.

Putnam, Robert. 2000. Bowling Alone: The Collapse and Revival of American Community. New York, NY: Simon and Schuster. 
Putnam, Robert. 2007. "E Pluribus Unum: Diversity and Community in the Twenty-First Century; the 2006 Johan Skytte Prize Lecture." Scandinavian Political Studies 30(2):13774 .

Raudenbush, Stephen W. and Anthony Bryk. 2002. Hierarchical Linear Models: Applications and Data Analysis Methods. London: Sage, 2nd edition.

Reardon, Sean and Kendra Bischoff. 2011. "Income Inequality and Income Segregation." American Journal of Sociology 116(4):1092-1153.

Richard, Burkhauser, Shuaizhang Feng, Stephen Jenkins, and Jeff Larrimore. 2009. "Recent Trends in Top Incomes Shares in the USA: Reconciling Estimates from March CPS and IRS Tax Return Data." NBER Working Paper 15320.

Ridgeway, Cecilia. 2014. "Why Status Matters for Inequality." American Sociological Review 79:1-16.

Robinson, Robert V. and Elton F. Jackson. 2001. "Is Trust in Others Declining in America? An Age-Period-Cohort Analysis." Social Science Research 30:117-145.

Rothstein, Bo and Eric M. Uslaner. 2005. "All for All: Equality, Corruption, and Social Trust." World Politics 58(1):41-72.

Saez, Emmanuel and Gabriel Zucman. 2016. "Wealth Inequality in the United States Since 1913: Evidence from Capitalized Income Tax Data." Quarterly Journal of Economics 131 (2):519-578.

Sampson, Ralph J., Jeffrey D. Morenoff, and Thomas Gannon-Rowley. 2002. "Assessing 'Neighborhood Effects': Social Processes and New Directions in Research." Annual Review of Sociology 28(1):443-478.

Schmidt-Catran, Alexander W. and Malcolm Fairbrother. 2016. "The Random Effects in Multilevel Models: Getting Them Wrong and Getting Them Right." European Sociological Review 32(1):23-38.

Schröder, Martin. 2016. "Article Navigation How Income Inequality Influences Life Satisfaction: Hybrid Effects Evidence from the German SOEP." European Sociological Review 32 (2):307-320.

Simmel, Georg. 1950. The Sociology of Georg Simmel. Edited by Kurt H. Wolf. New York: The Free Press.

Simpson, Brent. 2006. "The Poverty of Trust in the Southern United States." Social Forces 84:1625-1638.

Simpson, Brent, Tucker McGrimmon, and Kyle Irwin. 2007. "Are Blacks Really Less Trusting Than Whites? Revisiting the Race and Trust Question." Social Forces 86:525-552.

Smith, Sandra Susan. 2010. "Race and Trust." Annual Review of Sociology 36:453-475. 
Smith, Tom, Peter Marsden, Michael Hout, and Jibum Kim. 2013. General Social Surveys, 1972-2012. Chicago: National Opinion Research Center [producer]; Storrs, CT: The Roper Center for Public Opinion Research, University of Connecticut [distributor].

Smith, Tom W. 1997. "Factors Relating to Misanthropy in Contemporary American Society." Social Science Research 26(2):170-196.

Stolle, Dietlind, Stuart Soroka, and Richard Johnston. 2008. "When Does Diversity Erode Trust? Neighborhood Diversity, Interpersonal Trust and the Mediating Effect of Social Interactions." Political Studies 56(1):57-75.

Stone, Chad, Danilo Trisi, Arloc Sherman, and Emily Horton. 2016. "A Guide to Statistics on Historical Trends in Income Inequality." Technical report, Center on Budget and Policy Priorities.

Twenge, Jean M., W. Keith Campbell, and Nathan T. Carter. 2014. "Declines in Trust in Others and Confidence in Institutions Among American Adults and Late Adolecents, 1972-2012." Psychological Science 25(10):1914-1923.

Uslaner, Eric. 2002. The Moral Foundations of Trust. Cambridge University Press.

VanderWeele, Tyler and Stijn Vansteelandt. 2009. "Conceptual Issues Concerning Mediation, Interventions and Composition." Statistics and Its Interface 2:457-468.

Veblen, Thorstein. [1899] 1963. A Theory of the Leisure Class: An Economic Study of Institutions. New York: New American Library.

Walasek, Lukasz and Gordon D. A. Brown. 2015. "Income Inequality and Status Seeking Searching for Positional Goods in Unequal US States." Psychological Science 26(4):527533.

Walasek, Lukasz and Gordon D. A. Brown. 2016. "Income Inequality, Income, and Internet Searches for Status Goods: A Cross-National Study of the Association Between Inequality and Well-Being." Social Indicators Research 129:1001-1014.

Warren, Mark (ed.). 1999. Democracy and Trust. Cambridge: Cambridge University Press.

Wilkinson, Richard and Kate Pickett. 2009. "Income Inequality and Social Dysfunction." Annual Review of Sociology 35:493-511.

Wilkinson, Richard and Kate Pickett. 2017. "The Enemy Between Us: The Psychological and Social Costs of Inequality." European Journal of Social Psychology 47(1):11-24. 


\section{Appendix}

Table A1: Coefficients (Log Odds) from Models of Binary Trust with Top 1\% Income Share and Bottom 99\% Gini Measures

\begin{tabular}{|c|c|c|c|c|c|c|}
\hline \multirow[b]{2}{*}{ Between State Top 1\% share (SD) } & \multicolumn{2}{|c|}{$\begin{array}{c}(1) \\
\text { Trust (binary) }\end{array}$} & \multicolumn{2}{|c|}{$\begin{array}{c}(2) \\
\text { Trust (binary) }\end{array}$} & \multicolumn{2}{|c|}{$\begin{array}{c}(3) \\
\text { Trust (binary) }\end{array}$} \\
\hline & -0.11 & $(0.081)$ & -0.075 & $(0.068)$ & -0.052 & $(0.073)$ \\
\hline Within State Top 1\% share (SD) & $-0.21^{* * *}$ & $(0.052)$ & -0.043 & $(0.041)$ & 0.026 & $(0.056)$ \\
\hline Between State Gini $99 \%$ (SD) & -0.063 & $(0.087)$ & 0.033 & $(0.087)$ & 0.077 & $(0.088)$ \\
\hline Within State Gini 99\% (SD) & $-0.15^{* * *}$ & $(0.019)$ & $-0.046^{+}$ & $(0.024)$ & -0.013 & $(0.040)$ \\
\hline $\log ($ income $)$ & $0.21^{* * *}$ & $(0.019)$ & $0.21^{* * *}$ & $(0.019)$ & $0.21^{* * *}$ & $(0.019)$ \\
\hline Female & $-0.10^{* *}$ & $(0.032)$ & $-0.10^{* *}$ & $(0.032)$ & $-0.11^{* * *}$ & $(0.032)$ \\
\hline Age (years) & $0.043^{* * *}$ & $(0.0053)$ & $0.043^{* * *}$ & $(0.0053)$ & $0.043^{* * *}$ & $(0.0053)$ \\
\hline$($ Age x Age $) / 100$ & $-0.025^{* * *}$ & $(0.0053)$ & $-0.025^{* * *}$ & $(0.0054)$ & $-0.025^{* * *}$ & $(0.0054)$ \\
\hline Non-Hispanic white & 0 & $()$. & 0 & $()$. & 0 & (.) \\
\hline Non-Hispanic black & $-1.05^{* * *}$ & $(0.083)$ & $-1.05^{* * *}$ & $(0.083)$ & $-1.07^{* * *}$ & $(0.083)$ \\
\hline Non-Hispanic other & $-0.51^{* * *}$ & $(0.065)$ & $-0.51^{* * *}$ & $(0.066)$ & $-0.52^{* * *}$ & $(0.067)$ \\
\hline Hispanic & $-0.51^{* * *}$ & $(0.061)$ & $-0.50^{* * *}$ & $(0.061)$ & $-0.51^{* * *}$ & $(0.060)$ \\
\hline Married & 0 & $()$. & 0 & $()$. & 0 & $()$. \\
\hline Widowed & -0.10 & $(0.064)$ & $-0.10^{+}$ & $(0.063)$ & -0.10 & $(0.062)$ \\
\hline Divorced & $-0.14^{* *}$ & $(0.047)$ & $-0.14^{* *}$ & $(0.047)$ & $-0.13^{* *}$ & $(0.047)$ \\
\hline Separated & $-0.24^{* *}$ & $(0.077)$ & $-0.24^{* *}$ & $(0.078)$ & $-0.24^{* *}$ & $(0.079)$ \\
\hline Never Married & 0.052 & $(0.051)$ & 0.058 & $(0.051)$ & 0.055 & $(0.051)$ \\
\hline Num of adults & -0.020 & $(0.017)$ & -0.021 & $(0.017)$ & -0.022 & $(0.017)$ \\
\hline Num of children & -0.0053 & $(0.0075)$ & -0.0056 & $(0.0076)$ & -0.0052 & $(0.0075)$ \\
\hline Religious service attendance & $0.027^{* * *}$ & $(0.0071)$ & $0.026^{* * *}$ & $(0.0071)$ & $0.025^{* * *}$ & $(0.0071)$ \\
\hline Years of education & $0.17^{* * *}$ & $(0.0066)$ & $0.17^{* * *}$ & $(0.0067)$ & $0.17^{* * *}$ & $(0.0067)$ \\
\hline Urban & 0 & $()$. & 0 & $()$. & 0 & $()$. \\
\hline Suburban & -0.042 & $(0.037)$ & -0.039 & $(0.037)$ & -0.044 & $(0.037)$ \\
\hline Rural & 0.020 & $(0.063)$ & 0.030 & $(0.061)$ & 0.029 & $(0.060)$ \\
\hline State income/capita & -0.011 & $(0.0089)$ & 0.0052 & $(0.0096)$ & 0.0056 & $(0.010)$ \\
\hline State percent foreign born & -0.027 & $(0.66)$ & 0.19 & $(0.61)$ & 0.20 & $(0.61)$ \\
\hline State population density (logged) & -0.016 & $(0.047)$ & -0.023 & $(0.045)$ & -0.0073 & $(0.045)$ \\
\hline State percent black & -0.85 & $(0.58)$ & $-0.86^{+}$ & $(0.51)$ & $-1.00^{*}$ & $(0.50)$ \\
\hline Southern state & $-0.35^{* *}$ & $(0.12)$ & $-0.30^{* *}$ & $(0.099)$ & $-0.29^{* *}$ & $(0.097)$ \\
\hline Year (linear) & & & $-0.023^{* * *}$ & $(0.0040)$ & & \\
\hline Constant & $-5.47^{* * *}$ & $(0.29)$ & $39.1^{* * *}$ & $(7.83)$ & $-5.30^{* * *}$ & $(0.25)$ \\
\hline $\operatorname{var}($ State $)$ & $0.032^{*}$ & $(0.013)$ & $0.026^{*}$ & $(0.011)$ & $0.027^{*}$ & $(0.011)$ \\
\hline $\operatorname{var}($ State-year) & $0.040^{* * *}$ & $(0.0093)$ & $0.033^{* * *}$ & $(0.0079)$ & 0.0092 & $(0.0076)$ \\
\hline Year fixed effects & No & & No & & Yes & \\
\hline Observations & 31857 & & 31857 & & 31857 & \\
\hline
\end{tabular}

Standard errors in parentheses

${ }^{*} p<.05,{ }^{* *} p<.01,{ }^{* * *} p<.001$

Note: Results are from a multilevel logistic regression model. 
Table A2: Coefficients from Models of Trust Scale with Top 1\% Income Share and Bottom 99\% Gini Measures

\begin{tabular}{|c|c|c|c|c|c|c|}
\hline \multirow[b]{2}{*}{ Between State Top $1 \%$ share (SD) } & \multicolumn{2}{|c|}{$\begin{array}{c}(1) \\
\text { Trust (scale) }\end{array}$} & \multicolumn{2}{|c|}{$\begin{array}{c}(2) \\
\text { Trust (scale) }\end{array}$} & \multicolumn{2}{|c|}{$\begin{array}{c}(3) \\
\text { Trust (scale) }\end{array}$} \\
\hline & $-0.15^{+}$ & $(0.080)$ & $-0.13^{+}$ & $(0.073)$ & -0.11 & $(0.076)$ \\
\hline Within State Top 1\% share (SD) & $-0.24^{* * *}$ & $(0.048)$ & $-0.13^{* *}$ & $(0.041)$ & -0.070 & $(0.051)$ \\
\hline Between State Gini 99\% (SD) & -0.060 & $(0.077)$ & 0.0031 & $(0.077)$ & 0.045 & $(0.077)$ \\
\hline Within State Gini 99\% (SD) & $-0.14^{* * *}$ & $(0.018)$ & $-0.069^{* *}$ & $(0.025)$ & -0.015 & $(0.035)$ \\
\hline $\log ($ income $)$ & $0.21^{* * *}$ & $(0.013)$ & $0.21^{* * *}$ & $(0.014)$ & $0.21^{* * *}$ & $(0.014)$ \\
\hline Female & $0.17^{* * *}$ & $(0.026)$ & $0.17^{* * *}$ & $(0.026)$ & $0.16^{* * *}$ & $(0.026)$ \\
\hline Age (years) & $0.042^{* * *}$ & $(0.0040)$ & $0.042^{* * *}$ & $(0.0040)$ & $0.043^{* * *}$ & $(0.0040)$ \\
\hline$($ Age $x$ Age $) / 100$ & $-0.016^{* * *}$ & $(0.0041)$ & $-0.016^{* * *}$ & $(0.0041)$ & $-0.017^{* * *}$ & $(0.0040)$ \\
\hline Non-Hispanic white & 0 & $()$. & 0 & $()$. & 0 & $()$. \\
\hline Non-Hispanic black & $-1.05^{* * *}$ & $(0.078)$ & $-1.05^{* * *}$ & $(0.078)$ & $-1.06^{* * *}$ & $(0.077)$ \\
\hline Non-Hispanic other & $-0.38^{* * *}$ & $(0.085)$ & $-0.37^{* * *}$ & $(0.086)$ & $-0.38^{* * *}$ & $(0.089)$ \\
\hline Hispanic & $-0.49^{* * *}$ & $(0.069)$ & $-0.48^{* * *}$ & $(0.069)$ & $-0.48^{* * *}$ & $(0.068)$ \\
\hline Married & 0 & $()$. & 0 & $()$. & 0 & $()$. \\
\hline Widowed & $-0.13^{*}$ & $(0.055)$ & $-0.14^{*}$ & $(0.055)$ & $-0.13^{*}$ & $(0.054)$ \\
\hline Divorced & $-0.25^{* * *}$ & $(0.030)$ & $-0.24^{* * *}$ & $(0.030)$ & $-0.24^{* * *}$ & $(0.030)$ \\
\hline Separated & $-0.26^{* * *}$ & $(0.063)$ & $-0.26^{* * *}$ & $(0.063)$ & $-0.26^{* * *}$ & $(0.064)$ \\
\hline Never Married & $0.11^{*}$ & $(0.046)$ & $0.11^{*}$ & $(0.046)$ & $0.11^{*}$ & $(0.045)$ \\
\hline Num of adults & -0.020 & $(0.015)$ & -0.020 & $(0.015)$ & -0.021 & $(0.015)$ \\
\hline Num of children & 0.0047 & $(0.0084)$ & 0.0045 & $(0.0084)$ & 0.0047 & $(0.0083)$ \\
\hline Religious service attendance & $0.056^{* * *}$ & $(0.0070)$ & $0.055^{* * *}$ & $(0.0069)$ & $0.055^{* * *}$ & $(0.0069)$ \\
\hline Years of education & $0.17^{* * *}$ & $(0.0053)$ & $0.17^{* * *}$ & $(0.0054)$ & $0.17^{* * *}$ & $(0.0055)$ \\
\hline Urban & 0 & $()$. & 0 & $()$. & 0 & $()$. \\
\hline Suburban & -0.050 & $(0.042)$ & -0.048 & $(0.042)$ & -0.055 & $(0.043)$ \\
\hline Rural & 0.086 & $(0.061)$ & 0.092 & $(0.061)$ & 0.088 & $(0.059)$ \\
\hline State income/capita & 0.0028 & $(0.0082)$ & 0.014 & $(0.0092)$ & $0.019^{*}$ & $(0.0097)$ \\
\hline State percent foreign born & -0.18 & $(0.73)$ & 0.035 & $(0.76)$ & -0.092 & $(0.79)$ \\
\hline State population density (logged) & -0.028 & $(0.041)$ & -0.035 & $(0.038)$ & -0.033 & $(0.037)$ \\
\hline State percent black & -0.67 & $(0.62)$ & -0.69 & $(0.56)$ & -0.73 & $(0.53)$ \\
\hline Southern state & $-0.38^{* * *}$ & $(0.10)$ & $-0.34^{* * *}$ & $(0.090)$ & $-0.32^{* * *}$ & $(0.087)$ \\
\hline Year (linear) & & & $-0.015^{* * *}$ & $(0.0033)$ & & \\
\hline Constant & $-2.57^{* * *}$ & $(0.26)$ & $27.2^{* * *}$ & $(6.55)$ & $-2.70^{* * *}$ & $(0.23)$ \\
\hline $\operatorname{var}($ State $)$ & $0.034^{* * *}$ & $(0.013)$ & $0.028^{* * *}$ & $(0.010)$ & $0.027^{* * *}$ & $(0.0100)$ \\
\hline $\operatorname{var}($ State-year) & $0.053^{* * *}$ & $(0.0092)$ & $0.051^{* * *}$ & $(0.0091)$ & $0.032^{* * *}$ & $(0.010)$ \\
\hline $\operatorname{var}($ Residual $)$ & $4.02^{* * *}$ & $(0.033)$ & $4.02^{* * *}$ & $(0.033)$ & $4.03^{* * *}$ & $(0.033)$ \\
\hline Year fixed effects & No & & No & & Yes & \\
\hline Observations & 29457 & & 29457 & & 29457 & \\
\hline
\end{tabular}

Standard errors in parentheses

${ }^{*} p<.05,{ }^{* *} p<.01,{ }^{* * *} p<.001$

Note: Results are from a multilevel regression model. 
Table A3: Coefficients from Logit Models of Trust with State Fixed Effects

\begin{tabular}{|c|c|c|c|c|c|c|}
\hline & (1) & & $(2)$ & & $(3)$ & \\
\hline \multicolumn{7}{|l|}{ Trust (binary) } \\
\hline State Gini & $-3.76^{* * *}$ & $(0.53)$ & $-1.14^{*}$ & $(0.57)$ & 0.32 & $(0.98)$ \\
\hline $\log$ (income) & $0.21^{* * *}$ & $(0.020)$ & $0.20^{* * *}$ & $(0.019)$ & $0.21^{* * *}$ & $(0.019)$ \\
\hline Female & $-0.099^{* *}$ & $(0.032)$ & $-0.099^{* *}$ & $(0.032)$ & $-0.11^{* * *}$ & $(0.032)$ \\
\hline Age (years) & $0.043^{* * *}$ & $(0.0052)$ & $0.043^{* * *}$ & $(0.0053)$ & $0.043^{* * *}$ & $(0.0053)$ \\
\hline$($ Age x Age) $/ 100$ & $-0.025^{* * *}$ & $(0.0053)$ & $-0.025^{* * *}$ & $(0.0054)$ & $-0.025^{* * *}$ & $(0.0054)$ \\
\hline Non-Hispanic white & 0 & $()$. & 0 & $()$. & 0 & $()$. \\
\hline Non-Hispanic black & $-1.05^{* * *}$ & $(0.083)$ & $-1.05^{* * *}$ & $(0.083)$ & $-1.06^{* * *}$ & $(0.084)$ \\
\hline Non-Hispanic other & $-0.49^{* * *}$ & $(0.066)$ & $-0.49^{* * *}$ & $(0.066)$ & $-0.51^{* * *}$ & $(0.068)$ \\
\hline Hispanic & $-0.50^{* * *}$ & $(0.061)$ & $-0.49^{* * *}$ & $(0.062)$ & $-0.50^{* * *}$ & $(0.060)$ \\
\hline Married & 0 & $()$. & 0 & $()$. & 0 & $()$. \\
\hline Widowed & -0.10 & $(0.063)$ & $-0.10^{+}$ & $(0.063)$ & -0.10 & $(0.063)$ \\
\hline Divorced & $-0.14^{* *}$ & $(0.046)$ & $-0.13^{* *}$ & $(0.047)$ & $-0.13^{* *}$ & $(0.047)$ \\
\hline Separated & $-0.24^{* *}$ & $(0.078)$ & $-0.24^{* *}$ & $(0.078)$ & $-0.25^{* *}$ & $(0.080)$ \\
\hline Never Married & 0.056 & $(0.050)$ & 0.059 & $(0.051)$ & 0.052 & $(0.051)$ \\
\hline Num of adults & -0.019 & $(0.017)$ & -0.020 & $(0.017)$ & -0.022 & $(0.017)$ \\
\hline Num of children & -0.0051 & $(0.0074)$ & -0.0055 & $(0.0075)$ & -0.0056 & $(0.0075)$ \\
\hline Religious service attendance & $0.027^{* * *}$ & $(0.0072)$ & $0.026^{* * *}$ & $(0.0072)$ & $0.025^{* * *}$ & $(0.0072)$ \\
\hline Years of education & $0.16^{* * *}$ & $(0.0065)$ & $0.17^{* * *}$ & $(0.0066)$ & $0.17^{* * *}$ & $(0.0067)$ \\
\hline Urban & 0 & $()$. & 0 & $()$. & 0 & $()$. \\
\hline Suburban & -0.041 & $(0.038)$ & -0.037 & $(0.038)$ & -0.044 & $(0.038)$ \\
\hline Rural & 0.014 & $(0.063)$ & 0.017 & $(0.061)$ & 0.019 & $(0.060)$ \\
\hline State income/capita & -0.0084 & $(0.0070)$ & 0.0078 & $(0.0065)$ & 0.0093 & $(0.010)$ \\
\hline State percent foreign born & $1.54^{+}$ & $(0.81)$ & $1.26^{+}$ & $(0.67)$ & 1.03 & $(0.70)$ \\
\hline State population density (logged) & -0.26 & $(0.18)$ & $0.21^{+}$ & $(0.11)$ & $0.26^{*}$ & $(0.13)$ \\
\hline State percent black & $-5.11^{*}$ & $(1.99)$ & -1.78 & $(1.76)$ & -1.80 & $(1.75)$ \\
\hline Southern state & 0.92 & $(0.81)$ & -1.09 & $(0.70)$ & -1.14 & $(0.74)$ \\
\hline Year (linear) & & & $-0.026^{* * *}$ & $(0.0031)$ & & \\
\hline Constant & $-2.83^{* * *}$ & $(0.43)$ & $47.1^{* * *}$ & $(5.96)$ & $-5.81^{* * *}$ & $(0.60)$ \\
\hline Year fixed effects & No & & No & & Yes & \\
\hline State fixed effects & $Y e s$ & & Yes & & Yes & \\
\hline Observations & 31857 & & 31857 & & 31857 & \\
\hline
\end{tabular}

Standard errors in parentheses

${ }^{*} p<.05,{ }^{* *} p<.01,{ }^{* * *} p<.001$

Note: State fixed effects models. Including clustering and sampling weights. 
Table A4: Coefficients from Models of Trust Scale with State Fixed Effects

\begin{tabular}{|c|c|c|c|c|c|c|}
\hline & $(1)$ & & $(2)$ & & $(3)$ & \\
\hline State Gini & $-3.63^{* * *}$ & $(0.49)$ & $-2.34^{* * *}$ & $(0.56)$ & -0.66 & $(1.01)$ \\
\hline $\log ($ income $)$ & $0.21^{* * *}$ & $(0.013)$ & $0.20^{* * *}$ & $(0.013)$ & $0.21^{* * *}$ & $(0.014)$ \\
\hline Female & $0.17^{* * *}$ & $(0.027)$ & $0.17^{* * *}$ & $(0.026)$ & $0.17^{* * *}$ & $(0.026)$ \\
\hline Age (years) & $0.042^{* * *}$ & $(0.0040)$ & $0.042^{* * *}$ & $(0.0040)$ & $0.043^{* * *}$ & $(0.0040)$ \\
\hline$($ Age x Age) $/ 100$ & $-0.016^{* * *}$ & $(0.0040)$ & $-0.016^{* * *}$ & $(0.0040)$ & $-0.017^{* * *}$ & $(0.0040)$ \\
\hline Non-Hispanic white & 0 & $()$. & 0 & $()$. & 0 & $()$. \\
\hline Non-Hispanic black & $-1.06^{* * *}$ & $(0.079)$ & $-1.06^{* * *}$ & $(0.079)$ & $-1.06^{* * *}$ & $(0.077)$ \\
\hline Non-Hispanic other & $-0.38^{* * *}$ & $(0.082)$ & $-0.37^{* * *}$ & $(0.082)$ & $-0.38^{* * *}$ & $(0.087)$ \\
\hline Hispanic & $-0.47^{* * *}$ & $(0.073)$ & $-0.46^{* * *}$ & $(0.073)$ & $-0.47^{* * *}$ & $(0.069)$ \\
\hline Married & 0 & $()$. & 0 & $()$. & 0 & $()$. \\
\hline Widowed & $-0.14^{*}$ & $(0.056)$ & $-0.14^{*}$ & $(0.056)$ & $-0.13^{*}$ & $(0.055)$ \\
\hline Divorced & $-0.25^{* * *}$ & $(0.029)$ & $-0.24^{* * *}$ & $(0.029)$ & $-0.24^{* * *}$ & $(0.030)$ \\
\hline Separated & $-0.27^{* * *}$ & $(0.065)$ & $-0.27^{* * *}$ & $(0.064)$ & $-0.27^{* * *}$ & $(0.065)$ \\
\hline Never Married & $0.12^{*}$ & $(0.046)$ & $0.12^{*}$ & $(0.046)$ & $0.11^{*}$ & $(0.045)$ \\
\hline Num of adults & -0.020 & $(0.015)$ & -0.020 & $(0.015)$ & -0.021 & $(0.015)$ \\
\hline Num of children & 0.0049 & $(0.0084)$ & 0.0047 & $(0.0084)$ & 0.0044 & $(0.0083)$ \\
\hline Religious service attendance & $0.056^{* * *}$ & $(0.0069)$ & $0.056^{* * *}$ & $(0.0069)$ & $0.055^{* * *}$ & $(0.0070)$ \\
\hline Years of education & $0.17^{* * *}$ & $(0.0055)$ & $0.17^{* * *}$ & $(0.0056)$ & $0.17^{* * *}$ & $(0.0056)$ \\
\hline Urban & 0 & $()$. & 0 & $()$. & 0 & $()$. \\
\hline Suburban & -0.040 & $(0.044)$ & -0.039 & $(0.045)$ & -0.049 & $(0.045)$ \\
\hline Rural & 0.086 & $(0.063)$ & 0.088 & $(0.063)$ & 0.081 & $(0.060)$ \\
\hline State income/capita & -0.0012 & $(0.0055)$ & 0.0069 & $(0.0060)$ & 0.0044 & $(0.0083)$ \\
\hline State percent foreign born & 0.96 & $(1.04)$ & 0.81 & $(0.98)$ & 0.40 & $(0.91)$ \\
\hline State population density (logged) & $-0.37^{*}$ & $(0.18)$ & -0.12 & $(0.16)$ & -0.049 & $(0.15)$ \\
\hline State percent black & -2.16 & $(1.70)$ & -0.54 & $(1.49)$ & -0.33 & $(1.53)$ \\
\hline Southern state & 0.72 & $(0.60)$ & -0.30 & $(0.55)$ & -0.47 & $(0.56)$ \\
\hline Year (linear) & & & $-0.013^{* * *}$ & $(0.0030)$ & & \\
\hline Constant & 0.11 & $(0.39)$ & $24.8^{* * *}$ & $(5.72)$ & $-2.06^{* *}$ & $(0.64)$ \\
\hline Year fixed effects & No & & No & & Yes & \\
\hline State fixed effects & Yes & & Yes & & Yes & \\
\hline Observations & 29457 & & 29457 & & 29457 & \\
\hline
\end{tabular}

Standard errors in parentheses

${ }^{*} p<.05,{ }^{* *} p<.01,{ }^{* * *} p<.001$

Note: State fixed effects models. Including clustering and sampling weights. 